(C) The Authors 2019. This is an Open Access article, distributed under the terms of the Creative Commons Attribution licence (http:// creativecommons.org/licenses/by/4.0/), which permits unrestricted re-use, distribution, and reproduction in any medium, provided the original work is properly cited.

\title{
n-3 Canola oil effectively replaces fish oil as a new safe dietary source of DHA in feed for juvenile Atlantic salmon
}

\author{
Bente Ruyter $^{1 *}$, Nini H. Sissener ${ }^{2}$, Tone-Kari Østbye ${ }^{1}$, Cedric J. Simon ${ }^{3}$, Aleksei Krasnov ${ }^{1}$, Marta Bou $^{1}$, \\ Monica Sanden ${ }^{2}$, Peter D. Nichols ${ }^{4}$, Esmail Lutfi ${ }^{1}$ and Gerd M. Berge ${ }^{1}$ \\ ${ }^{1}$ Nofima (Norwegian Institute of Food, Fisheries and Aquaculture Research), 1432 Ås, Norway \\ ${ }^{2}$ Institute of Marine Research, 5817 Bergen, Norway \\ ${ }^{3}$ CSIRO Agriculture and Food, QLD Biosciences Precinct, St Lucia, QLD 4067, Australia \\ ${ }^{4}$ CSIRO Oceans and Atmosphere, Hobart, TAS 7000, Australia
}

(Submitted 4 June 2019 - Final revision received 2 September 2019 - Accepted 3 September 2019)

\section{Abstract}

Limited availability of fish oils (FO), rich in $n-3$ long-chain $\left(\geq C_{20}\right)$ PUFA, is a major constraint for further growth of the aquaculture industry. Long-chain $n-3$ rich oils from crops GM with algal genes are promising new sources for the industry. This project studied the use of a newly developed $n$ - 3 canola oil (DHA-CA) in diets of Atlantic salmon fingerlings in freshwater. The DHA-CA oil has high proportions of the $n$ - 3 fatty acids (FA) $18: 3 n-3$ and DHA and lower proportions of $n-6$ FA than conventional plant oils. Levels of phytosterols, vitamin E and minerals in the DHA-CA were within the natural variation of commercial canola oils. Pesticides, mycotoxins, polyaromatic hydrocarbons and heavy metals were below lowest qualifiable concentration. Two feeding trials were conducted to evaluate effects of two dietary levels of DHA-CA compared with two dietary levels of FO at two water temperatures. Fish increased their weight approximately 20 -fold at $16^{\circ} \mathrm{C}$ and 12 -fold at $12^{\circ} \mathrm{C}$ during the experimental periods, with equal growth in salmon fed the FO diets compared with DHA-CA diets. Salmon fed DHA-CA diets had approximately the same EPA+DHA content in whole body as salmon fed FO diets. Gene expression, lipid composition and oxidative stress-related enzyme activities showed only minor differences between the dietary groups, and the effects were mostly a result of dietary oil level, rather than the oil source. The results demonstrated that DHA-CA is a safe and effective replacement for FO in diets of Atlantic salmon during the sensitive fingerling life-stage.

Key words: Atlantic salmon: $n$-3 Fatty acids: EPA: DHA: GM crops: Canola oil

Diets for farmed Atlantic salmon, Salmo salar, have changed considerably during the last decades. In Norway, although $90 \%$ of the ingredients were of marine origin in the 1990s, current diets only contain approximately $30 \%$ marine ingredients ${ }^{(1)}$. This situation is very similar in Chile, Canada and Australia, whereas salmon diets used in Scotland in 2013/2014 contained $60 \%$ plant ingredients and $40 \%$ marine ingredients on average ${ }^{(2)}$. The shift from marine to plant ingredients, or in some cases land animal by-products, has been driven by the need of the feed producers to reduce dietary reliance on the finite marine-derived ingredients, fish oil (FO) and fishmeal (FM) to secure global aquaculture production ${ }^{(3)}$. However, vegetable oils are naturally devoid of the nutritionally beneficial $n$-3 ( $n$ - 3 ) long-chain $\left(\geq \mathrm{C}_{20}\right.$ ) PUFA (LC-PUFA), EPA (20:5n-3) and DHA (22:6n-3), and cannot be used as the sole oil source in fish diets with a low FM content, since EPA and DHA are essential fatty acids (FA) in salmon diets ${ }^{(4,5)}$. The physiological relevance of these FA is well-recognised, being involved in maintaining the structural and functional integrity of cellular membranes, acting as precursors of important metabolites, such as eicosanoids, and working as signalling molecules able to regulate the transcription of genes involved in lipid metabolism ${ }^{(6,7)}$.

The Norwegian, Scottish and Australian salmon industries have reported a significant decrease in the absolute amounts of EPA and DHA in salmon fillets and a concomitant increase in FA typical of terrestrial-derived lipid sources, reflecting the changes in the feed formulation throughout the years ${ }^{(1,2,8-10)}$. In addition, the high inclusion levels of vegetable and/or animal oils rich in $n-6 \mathrm{FA}$ in salmon diets result in an associated increase in the $n-6: n-3$ ratio in fish organs and tissues, including fish fillets $^{(11)}$. This is an important issue that might affect not only fish and human consumer health but also influence consumer perspectives towards farmed fish. Alternative sources of $n-3$ LC-PUFA oils are being pursued; however, neither oils from traditional oilseeds such as linseed nor the GM stearidonic acid

Abbreviations: Ctr-CA, control canola oil; DHA-CA, $n$-3-rich modified canola oil; FA, fatty acids; FM, fishmeal; FO, fish oil; LC-PUFA, long-chain ( $\geq \mathrm{C}_{20}$ ) PUFA; UPLC, ultra-performance liquid chromatography. 
(18: 4n-3) or EPA rich oils have so far shown efficient conversion to DHA in Atlantic salmon ${ }^{(12)}$.

In terrestrial GM plant oils, enriched levels of DHA have been achieved, combined with lower $n-6$ PUFA levels than occurs in conventional canola oils ${ }^{(12-15)}$. Today, close to $70 \%$ of the oil fraction in feeds for Atlantic salmon in Norway consists of canola oil, demonstrating that the fish already grow and perform well on canola oil-rich diets. In addition, several Atlantic salmon feeding studies using GM plant material from soyabean and maize have shown that they are as safe as commercial varieties (for a review, see Sissener et $\left.a l .{ }^{(16)}\right)$. GM camelina oil rich in EPA, although containing a high level of $n-6$ FA, has been tested in diets of post-smolt Atlantic salmon. This oil did not influence the fish performance relative to a FO diet; however, liver transcriptome analyses revealed that the response in fish was closer to the expected response to plant oils than to that of $\mathrm{FO}^{(17)}$. Some studies have shown that Atlantic salmon has a more defined requirement for DHA than for $\mathrm{EPA}^{(18-20)}$. When replacing conventional feed ingredients with new ingredients, it is important to ensure that they are as safe as traditional products.

In the present study, two separate feeding trials with DHA-CA oil were performed, one in Australia at a water temperature of $16^{\circ} \mathrm{C}$ and one in Norway at a lower water temperature of $12^{\circ} \mathrm{C}$. The overall study was undertaken to determine if the new DHA-CA oil containing enhanced levels of $n-3$ LC-PUFA and a lower level of $n$-6 LC-PUFA than conventional canola oils would influence growth, performance, health and $n$-3 LC-PUFA, content in different organs and tissues in Atlantic salmon fingerling.

\section{Materials and methods}

\section{Canola oils}

The DHA-CA tested in the experiment was obtained from Event NS-B50027-4, which is a modified canola (Brassica napus) line developed by Nuseed Pty. Ltd. The transgenic seeds were modified to produce the LC-PUFA - EPA and DHA; construct details are provided in Petrie et al. ${ }^{(15)}$. The crop used in this trial was grown in Australia during 2015 and 2016. The control canola oil (Ctr-CA) used in the diets was an Australian variety (Garnet) with an oil profile similar to that of the parent (untransformed) line from which NS-B50027-4 was derived. Oils were cold-pressed and filtered.

\section{Analyses of elements and undesirables in the oils}

Multielement determination of the oils was done by inductively coupled plasma $\mathrm{MS}^{(21)}$, while analysis of selected undesirable compounds was conducted by Eurofins ( $\mathrm{GmbH}$, Hamburg) using accredited methods (accreditation number D-PL-14602-01-00). Chlorinated pesticides (aldrin; chlordane, cis-; chlordane, oxy-; chlordane, trans-; dieldrin; endrin; $\gamma-\mathrm{HCH}$ (lindane); $\mathrm{HCH}$, $\alpha-; \mathrm{HCH}, \beta-; \mathrm{HCH}$, delta-; heptachlor; heptachlor epoxide, cis-; heptachlor epoxide, trans-; hexachlorobenzene (HCB); mirex; nonachlor, trans-; o,p'-DDD; o,p'-DDE; o,p'-DDT; octachlorstyrene; $\mathrm{p}$, $\mathrm{p}^{\prime}$-DDD; p,p'-DDE; p,p'-DDT; pentachlorobenzene; toxaphene parlar 26; toxaphene parlar 50; toxaphene parlar 62, endosulfan (- $\alpha,-\beta,-$ sulfat), toxaphene $-26,-50,-60)$, organophosphate pesticides
Table 1. Formulation and composition of the experimental diets used in the $16^{\circ} \mathrm{C}$ water temperature experiment ${ }^{*}$

\begin{tabular}{lcccc}
\hline & & & Low & High \\
& Low FO & High FO & DHA-CA & DHA-CA \\
\hline Formulation (\%) & & & & \\
Fishmeal & 79.00 & 79.00 & 79.00 & 79.00 \\
Wheat & 7.00 & 7.00 & 7.00 & 7.00 \\
Mineral mix & 0.59 & 0.59 & 0.59 & 0.59 \\
Vitamin mix & 1.92 & 1.92 & 1.92 & 1.92 \\
Carophyll pink & 0.01 & 0.01 & 0.01 & 0.01 \\
Choline chloride & 0.5 & 0.5 & 0.5 & 0.5 \\
Vitamin C & 0.14 & 0.14 & 0.14 & 0.14 \\
Vitamin E (50\%) & 0.03 & 0.03 & 0.03 & 0.03 \\
CaHPO & 1.00 & 1.00 & 1.00 & 1.00 \\
Betaine & 1.00 & 1.00 & 1.00 & 1.00 \\
Soya lecithin & 1.00 & 1.00 & 1.00 & 1.00 \\
Tuna oil & 1.6 & 3.2 & - & - \\
Control canola oil & 6.2 & 4.6 & 3.9 & 0.00 \\
DHA-CA & - & - & 3.9 & 7.8 \\
Origin of EPA+DHA (\% in diet) & & & & \\
Fishmeal & 1.90 & 1.90 & 1.90 & 1.90 \\
Tuna oil & 0.47 & 0.95 & - & - \\
DHA-CA & - & - & 0.47 & 0.94 \\
Chemical composition & & & & \\
DM & 94.2 & 94.2 & 93.1 & 94.0 \\
Fat & 16.2 & 16.2 & 16.7 & 17.0 \\
Protein & 58.7 & 59.6 & 60.0 & 58.7 \\
Ash & 11.7 & 11.6 & 11.7 & 11.8 \\
Gross energy (MJ/kg) & 21.4 & 21.5 & 21.6 & 21.5 \\
\hline
\end{tabular}

FO, fish oil; DHA-CA, $n$-3-rich modified canola oil.

* All ingredients were sourced from an Australian provider. The fishmeal used was a commercial fishmeal from South America (Peru and Chile) provided by Ridley Aquafeeds. The source of fish oil was tuna oil in order to more closely match the balance of EPA:DHA in control and test feeds. Feed pellets (three class sizes; $0.5-1.0 \mathrm{~mm}, 1.0-1.4 \mathrm{~mm}$, and $1.4-2.0 \mathrm{~mm}$ ) were prepared at the CSIRO Bribie Island Research Centre, QLD. The composition is an average of all three pellet sizes.

(119 compounds), 16 PAH-compounds (benzo(a)antracene, benzo(a)pyrene, benzo(b)fluoranthene, benzo(c)fluorene, benzo(ghi)perylene, benzo(j)fluoranthene benzo(k)fluoranthene, chrysene, cyclopenta(cd)pyrene, dibenz(ah)anthracene, indeno(1,2,3-cd)pyrene, 5-methylchrysene, dibenzo(a,e)pyrene, dibenzo(a,h)pyrene, dibenzo(a,i)pyrene and dibenzo(a,l)pyrene) and five lipid-soluble mycotoxins beauvericin and enniatin (A, A1, B and B1) were analysed in the oils.

\section{Experimental diets used in the 16 and $12^{\circ} \mathrm{C}$ trials}

Tables 1 and 2 show the formulation and chemical composition of the experimental diets. The four experimental diets for the 16 and $12^{\circ} \mathrm{C}$ trials were isoproteic (i.e. 59 and $57 \%$ ), isolipidic (approximately 17 and 20\%) and isoenergetic (approximately $21 \mathrm{MJ} / \mathrm{kg}$ for both experiments) (Tables 1 and 2). The diets for the two trials were both formulated to contain similar amounts of all nutrients which satisfied the dietary requirement of small fingerling salmon. The ingredients FM and FO used in the two trials came from different sources, and therefore there were some differences in the total quantity of EPA and DHA in their respective diets. The dietary treatments tested in both trials consisted of two diets containing low or high levels of FO and two diets containing low or high levels of DHA-CA oil. Within each temperature study, the FO-based diets were supplemented with standard (control) canola oil (Crt-CA) to provide a similar content of EPA+DHA to the diets containing DHA-CA at 50 and $100 \%$ of 
Table 2. Formulation and composition of the experimental diets used in the $12^{\circ} \mathrm{C}$ water temperature experiment

\begin{tabular}{|c|c|c|c|c|}
\hline & $\begin{array}{l}\text { Low } \\
\text { FO }\end{array}$ & $\begin{array}{l}\text { High } \\
\text { FO }\end{array}$ & $\begin{array}{l}\text { Low } \\
\text { DHA-CA }\end{array}$ & $\begin{array}{l}\text { High } \\
\text { DHA-CA }\end{array}$ \\
\hline \multicolumn{5}{|l|}{ Formulation (\%) } \\
\hline Fishmeal $^{\star}$ & $79 \cdot 00$ & $79 \cdot 00$ & 79.00 & 79.00 \\
\hline Wheat $†$ & $7 \cdot 50$ & 7.50 & 7.50 & $7 \cdot 50$ \\
\hline Mineral mix $\ddagger$ & 0.52 & 0.52 & 0.52 & 0.52 \\
\hline Vitamin mix§ & 2.00 & 2.00 & $2 \cdot 00$ & 2.00 \\
\hline $\begin{array}{c}\text { Monoammonium } \\
\text { phosphate§ }\end{array}$ & 1.00 & 1.00 & 1.00 & 1.00 \\
\hline Carophyll pink§ & 0.01 & 0.01 & 0.01 & 0.01 \\
\hline Vitamin $D_{3}(\mathrm{mg} / \mathrm{kg}) \S$ & 0.05 & 0.05 & 0.05 & 0.05 \\
\hline Vitamin $\mathrm{E} \S$ & 20 & 20 & 20 & 20 \\
\hline Vitamin $\mathrm{C} \S$ & 7 & 7 & 7 & 7 \\
\hline Betafin§ & 1.00 & 1.00 & 1.00 & 1.00 \\
\hline Soya lecithin || & 1.00 & 1.00 & 1.00 & 1.00 \\
\hline Fish oilq & $1 \cdot 72$ & 3.41 & 0.00 & 0.00 \\
\hline Control canola oil ${ }^{\star \star}$ & $6 \cdot 08$ & 4.39 & $3 \cdot 88$ & 0.00 \\
\hline $\mathrm{DHA}-\mathrm{CA}$ & 0.00 & 0.00 & 3.92 & $7 \cdot 79$ \\
\hline \multicolumn{5}{|l|}{ Origin of EPA+DHA (\% in diet) } \\
\hline Fishmeal & 1.62 & 1.62 & 1.62 & 1.62 \\
\hline Fish oil & 0.32 & 0.63 & 0.00 & 0.00 \\
\hline $\mathrm{DHA}-\mathrm{CA}$ & 0.00 & 0.00 & $0 \cdot 32$ & 0.63 \\
\hline \multicolumn{5}{|l|}{ Chemical composition } \\
\hline DM & 93.9 & 93.7 & 93.8 & 93.7 \\
\hline Fat & $20 \cdot 9$ & $20 \cdot 6$ & $20 \cdot 9$ & $20 \cdot 7$ \\
\hline Protein & $56 \cdot 8$ & $56 \cdot 3$ & $56 \cdot 4$ & $56 \cdot 6$ \\
\hline Ash & $13 \cdot 4$ & $13 \cdot 3$ & $13 \cdot 3$ & $13 \cdot 2$ \\
\hline Gross energy $(\mathrm{MJ} / \mathrm{kg})$ & $20 \cdot 9$ & $21 \cdot 0$ & $21 \cdot 0$ & $21 \cdot 0$ \\
\hline \multicolumn{5}{|l|}{ Sterol composition } \\
\hline Cholesterol (mg/kg) & 4227 & 4469 & 4028 & 3950 \\
\hline Sum phytosterols (mg/kg) & 497 & 378 & 671 & 739 \\
\hline $\begin{array}{l}\text { Campesterol } \\
\text { (\% of sum phytosterols) }\end{array}$ & $32 \cdot 8$ & $31 \cdot 0$ & $33 \cdot 7$ & $35 \cdot 4$ \\
\hline $\begin{array}{l}\beta \text {-Sitosterol } \\
\quad \text { (\% of sum phytosterols) }\end{array}$ & $48 \cdot 6$ & $48 \cdot 6$ & $48 \cdot 1$ & $45 \cdot 5$ \\
\hline $\begin{array}{l}\text { Brassicasterol } \\
\text { (\% of sum phytosterols) }\end{array}$ & $3 \cdot 3$ & 4.4 & $2 \cdot 3$ & $2 \cdot 0$ \\
\hline \multicolumn{5}{|l|}{ Vitamin $\mathrm{K}$ isomers $(\mathrm{mg} / \mathrm{kg})$} \\
\hline $\begin{array}{l}\text { Phylloquinone } \\
\left(\text { vitamin } \mathrm{K}_{1}\right)\end{array}$ & 0.05 & 0.04 & $0 \cdot 10$ & $0 \cdot 14$ \\
\hline $\begin{array}{l}\text { Menaquinone } \\
\quad\left(\text { vitamin } \mathrm{K}_{2}\right)\end{array}$ & 0.07 & 0.07 & 0.06 & 0.06 \\
\hline Menadione $\left(\mathrm{K}_{3}\right)$ & $5 \cdot 91$ & $5 \cdot 79$ & $5 \cdot 84$ & $5 \cdot 94$ \\
\hline
\end{tabular}

FO, fish oil; DHA-CA, $n$-3-rich modified canola oil.

* Nordsildmel.

† Norgesmøllene.

$\ddagger$ Individual minerals purchased from Vilomix and mixed by Nofima.

$\S$ Vilomix.

II Denofa.

I) Nordsildmel.

${ }^{* *}$ Australia, var. Garnet.

total oil supplementation. The FA compositions of diets for the two temperature trials are presented in Table 3. All diets were produced in four pellet sizes and were used in accordance with increasing fish size. Due to the high FM inclusion (79\%) and low supplemental oil inclusion $(7 \cdot 8 \%)$ in the fingerling diet formulations, phytosterols only contributed $8-16 \%$ of the total sterols (the rest being cholesterol) in the feeds (Table 2). The calculated levels of EPA+DHA provided by the ingredients used in the diets are provided in Tables 1 and 2 .

\section{Fish trials at 16 and $12^{\circ} \mathrm{C}$}

Atlantic salmon fingerlings with a mean weight of 0.83 (SD 0.02) g were the starting points for the $16^{\circ} \mathrm{C}$ trial in Australia (CSIRO
Table 3. Selected undesirables, phytosterols, vitamin $E$ isomers and fatty acids in the $n$-3-rich modified canola oil (DHA-CA) and the control canola oil (Ctr-CA)

\begin{tabular}{|c|c|c|}
\hline & DHA-CA & Ctr-CA \\
\hline \multicolumn{3}{|l|}{ Heavy metals (mg/kg) } \\
\hline Total As & $<0.009$ & $<0.009$ \\
\hline \multicolumn{3}{|c|}{ Polyaromatic hydrocarbons ( $\mu \mathrm{g} / \mathrm{kg}$ ) } \\
\hline Benzo(a)antracene & $<0.5$ & $<0.5$ \\
\hline Benzo(a)pyrene & $<0.5$ & $<0.5$ \\
\hline Benzo(b)fluoranthene & $<0.5$ & $<0.5$ \\
\hline Chrysene & $<0.5$ & $<0.5$ \\
\hline \multicolumn{3}{|c|}{ Organophsophate pesticides $(\mu \mathrm{g} / \mathrm{kg})$} \\
\hline Pirimiphos-methyl & $<20$ & $<20$ \\
\hline \multicolumn{3}{|l|}{ Lipid-soluble mycotoxins $(\mu \mathrm{g} / \mathrm{kg})$} \\
\hline Enniatin B & $<10$ & $<10$ \\
\hline \multicolumn{3}{|l|}{ Phytosterols } \\
\hline Sum phytosterols (mg/kg) & 9659 & 7878 \\
\hline Campesterol (\% of sum) & $39 \cdot 6$ & $34 \cdot 2$ \\
\hline$\beta$-Sitosterol ( $\%$ of sum) & 43.0 & 44.5 \\
\hline Brassicasterol (\% of sum) & 3.5 & $12 \cdot 2$ \\
\hline \multicolumn{3}{|l|}{ Vitamin E isomers (mg/kg) } \\
\hline$\alpha$-Tocopherol & 200 & 188 \\
\hline$\gamma$-Tocopherol & 330 & 283 \\
\hline$\delta$-Tocopherol & 6.7 & 6.9 \\
\hline$\beta$-Tocotrienol & 95 & 71 \\
\hline \multicolumn{3}{|l|}{ Vitamin $\mathrm{K}$ isomers (mg/kg) } \\
\hline Phylloquinone (vitamin $\mathrm{K}_{1}$ ) & 3.62 & 1.61 \\
\hline Menaquinone (vitamin $\mathrm{K}_{2}$ ) & 0.00 & 0.00 \\
\hline Menadione $\left(\mathrm{K}_{3}\right)$ & 0.00 & 0.00 \\
\hline \multicolumn{3}{|l|}{ Fatty acid composition (\%) } \\
\hline $16: 0$ & 4.6 & 3.9 \\
\hline $18: 0$ & 1.9 & 1.6 \\
\hline$\Sigma \mathrm{SFA}^{*}$ & $7 \cdot 4$ & $6 \cdot 7$ \\
\hline $18: 1 n-9$ & 38.7 & 63.6 \\
\hline $18: 1 n-7$ & $5 \cdot 6$ & 3.5 \\
\hline$\Sigma$ MUFA† & $49 \cdot 3$ & $69 \cdot 0$ \\
\hline $18: 2 n-6$ & $9 \cdot 0$ & $13 \cdot 1$ \\
\hline $18: 3 n-3$ & $20 \cdot 9$ & $10 \cdot 3$ \\
\hline $20: 5 n-3$ & 0.4 & 0.1 \\
\hline $22: 5 n-3$ & 0.8 & nd \\
\hline $22: 6 n-3$ & $8 \cdot 2$ & nd \\
\hline$\Sigma$ PUFA & $41 \cdot 1$ & 23.9 \\
\hline$\Sigma n-6$ & $10 \cdot 0$ & $13 \cdot 3$ \\
\hline$\Sigma n-3$ & $30 \cdot 6$ & $10 \cdot 4$ \\
\hline
\end{tabular}

research facilities, Bribie Island). The Australian experimental fish fry was produced in September 2016 by the industry hatchery Salmon Enterprises of Tasmania Pty. Ltd (Saltas). Atlantic salmon fingerlings with a mean weight of 2.08 (SD 0.05) g were the starting points for the $12^{\circ} \mathrm{C}$ trial in Norway (Nofima research facilities Sunndalsøra). The Norwegian experimental fish fry was produced in January 2016 from the Broodstock population CrossBreed Stofnfiskur by the company SalmoBreed. The experimental fish were distributed in twelve tanks, 100 individuals per tank (300 litres) and 200 individuals per tank (150 litres) for the 16 and $12^{\circ} \mathrm{C}$ trials, respectively. The fibreglass tanks were equipped with automatic belt feeders. Freshwater at a constant $16(\mathrm{SD} 0 \cdot 1)^{\circ} \mathrm{C}$ and $12(\mathrm{SD} 0 \cdot 1)^{\circ} \mathrm{C}$ was supplied at flow rates of 3 and 5 litres/min, respectively. As the fish grew and $\mathrm{VO}_{2}$ increased, flow rate was increased stepwise. Fish were kept under constant light ( $24 \mathrm{~h}$ light-0 h dark) and fed every $10 \mathrm{~min}$. 
Feed was distributed according to the expected growth rate and a level of overfeeding that would allow all fish to feed $a d l i b$. The four experimental feeds were fed to triplicate groups of fish. Temperature was measured daily in six random tanks.

\section{Fish sampling in the 16 and $12{ }^{\circ} \mathrm{C}$ trials}

In the $16^{\circ} \mathrm{C}$ temperature trial, three individual samples of thirty pooled fish were taken initially and 100 fish per tank were bulk-weighed (20-30 fish at a time) on the same day. Fish were thereafter bulk weighed on days $0,34,56$ and 70 . On day 70 , ten fish per tank were sampled and pooled for whole-body proximal composition and $\mathrm{FA}$ analyses and stored at $-40^{\circ} \mathrm{C}$ until analyses.

In the $12^{\circ} \mathrm{C}$ trial, fish weights were bulk-weighed on days 0 , 27,41 and 83 . In the final sampling, five fish from each tank were sampled for whole-body analyses of total lipid and FA content and composition. Additionally, five fish per tank were sampled and used for other analyses. Blood samples were taken, livers and hearts were dissected out and weighed and organ indices were calculated. Samples of intestine, liver, heart and erythrocytes were frozen in liquid $\mathrm{N}_{2}$ and stored at $-70^{\circ} \mathrm{C}$ until analyses for FA composition, gene expression and enzyme activities.

\section{Chemical analysis in the 16 and $12^{\circ} \mathrm{C}$ trials}

Ten fish per tank were used for analyses of carcass chemical composition. Whole fish and DM content of the feeds were determined by gravimetric analysis following drying at $105^{\circ} \mathrm{C}$ for $16 \mathrm{~h}$. Ash content was determined based on mass change after combustion in a muffle furnace at $550^{\circ} \mathrm{C}$ for $16 \mathrm{~h}$. Measurement of total $\mathrm{N}_{2}$ content was undertaken using an elemental analyser (Flash 2000 Thermo Fisher Scientific), and data were used to calculate sample protein content based on $\mathrm{N} \times 6 \cdot 25$. Gross energy was determined by isoperibolic bomb calorimetry in a Parr 6200 oxygen bomb calorimeter (Par Instrument Company). Carbohydrate was calculated by difference.

\section{Fat content and fatty acid composition in the 16} and $12{ }^{\circ} \mathrm{C}$ trials

Total lipids were extracted from the dietary oil, erythrocytes, whole body, muscle, liver, intestine and diets, following the method described by Folch et $a l^{(22)}$. For the $16^{\circ} \mathrm{C}$ temperature trial, only whole body and diets were analysed. In each dietary group, fifteen fish were used for lipid analysis (five from each tank). The chloroform-methanol phase after Folch extraction was used for the analysis of the FA composition of total lipids using the method described by Mason et al. ${ }^{(23)}$. Briefly, the extract was dried under $\mathrm{N}_{2}$ gas, and residual lipid was transmethylated overnight with $2^{\prime}, 2^{\prime}$-dimethoxypropane, methanolic- $\mathrm{HCl}$ and benzene at room temperature. The methyl esters were separated and analysed using a gas chromatograph (Hewlett Packard 6890; HP) equipped with a split injector by using an SGE BPX70 capillary column (length, $60 \mathrm{~m}$; internal diameter, $0.25 \mathrm{~mm}$; and film thickness, $0.25 \mu \mathrm{m}$; SGE Analytical Science), flame ionisation detector and HP Chem Station software. The carrier gas was $\mathrm{He}$, and the injector and detector temperatures were both set at $280^{\circ} \mathrm{C}$. The oven temperature was increased from 50 to $180^{\circ} \mathrm{C}$ at the rate of $10^{\circ} \mathrm{C} / \mathrm{min}$ and then increased to $240^{\circ} \mathrm{C}$ at a rate of $0.7^{\circ} \mathrm{C} / \mathrm{min}$. Individual $\mathrm{FA}$ methyl esters were identified by referring to well-characterised standards. The relative amount of each FA was expressed as a percentage of the total amount of FA in the analysed sample, and the absolute amount of FA per $g$ of tissue was calculated using C23 : 0 methyl ester as the internal standard.

Similar methods were used for the high-temperature study, and while most FA were the same, a few different FA methyl esters were measured in the two standard protocols. In brief, $3 \mathrm{mg}$ of oil was esterified using methanol- $\mathrm{HCl}$ at $105^{\circ} \mathrm{C}$ for $60 \mathrm{~min}$ and then extracted with hexane for separation by GC (Agilent $6890 \mathrm{~N}$ ), using a DB-23 capillary column (length, $60 \mathrm{~m}$; internal diameter, $0.25 \mathrm{~mm}$; and film thickness, $0 \cdot 15 \mu \mathrm{m})$. The carrier gas was $\mathrm{H}_{2}$. Individual FA methyl esters were identified by referring to well-characterised standards and the Agilent RTL FAME Method, relative to C21 : 0 methyl ester as the internal standard.

\section{Gene expression analysis in the mid-intestine of fish reared at $12^{\circ} \mathrm{C}$}

Total RNA was isolated from mid-intestine using a PureLink Pro 96 RNA Purification Kit (Invitrogen), according to manufacturer's instructions. RNA was treated with PureLink DNase1 (ThermoFisher) to remove any contaminating DNA. The RNA concentration was measured using a NanoDrop ${ }^{\circledR}$ ND-1000 spectrophotometer (NanoDrop Technologies). Total RNA (900 ng) was reverse-transcribed into cDNA in a $20 \mu \mathrm{l}$ reaction using a TaqMan ${ }^{\circledR}$ reverse transcription reagents kit (Applied Biosystems) according to the manufacturer's protocol. Quantitative PCR was performed in a QuantStudio5 instrument (ThermoFisher), and the PCR master mix consisted of $0.5 \mu \mathrm{l}$ forward and $0.5 \mu$ l reverse primer (online Supplementary Table S1, final concentrations of $0.5 \mu \mathrm{m}$ ), $2 \mu \mathrm{l}$ of a 1:10 dilution of CDNA and $2.5 \mu \mathrm{l}$ PowerUp ${ }^{\mathrm{TM}}$ SYBR $^{\mathrm{TM}}$ Green Master Mix (ThermoFisher). All samples were analysed in duplicate with a non-template and non-RT enzyme control for each gene. The reaction was performed by incubating the samples at $95^{\circ} \mathrm{C}$ for $20 \mathrm{~s}$, forty cycles of $95^{\circ} \mathrm{C}$ for $1 \mathrm{~s}$ and $60^{\circ} \mathrm{C}$ for $20 \mathrm{~s}$. Primer efficiency was evaluated using 10 -fold serial dilutions of cDNA for each primer pair. The specificity of PCR amplification was confirmed by melting curve analysis $\left(95^{\circ} \mathrm{C}\right.$ for $1 \mathrm{~s}$ and $60^{\circ} \mathrm{C}$ for $20 \mathrm{~s}$, followed by an increase of $0.075^{\circ} \mathrm{C} / \mathrm{s}$ until $97^{\circ} \mathrm{C}$ ). Ef1a, rpol2 and etif3 were evaluated as reference genes, and etif3 was identified as the most stable. Relative expressions of mRNA were calculated using the $\Delta \Delta \mathrm{CT}$ method using etif3 as a reference gene ${ }^{(24)}$.

\section{Histology of intestine of fish reared at $12^{\circ} \mathrm{C}$}

Histological analysis of the mid-intestinal tissue was performed on fifteen samples from the mid intestine of each dietary group from the low-temperature trial, with samples collected at the final sampling, and fixed in $10 \%$ phosphate-buffered formalin and stored at $4^{\circ} \mathrm{C}$ until analysis. The samples were dehydrated and processed according to standard protocols. Paraplast-embedded samples were cut using a microtome $(5 \mu \mathrm{m})$ and stained with haematoxylin-eosin (Merck KGaA). Stained slides were examined using a standard Nikon Optiphot light microscope (Nikon). 
Images were captured using a MicroPublisher 3.3 RTV camera and analysed using QCapture Suite Software (QImaging). The sections were evaluated in a blinded manner to identify any pathological or other systematic variations in tissue morphology.

\section{Phytosterols, cholesterol, vitamin $\mathrm{E}$ and vitamin $\mathrm{K}$ analyses in the $12^{\circ} \mathrm{C}$ trial}

Phytosterols and cholesterol were analysed in the oils, feeds and in fish liver samples (six individual fish per tank with triplicate tanks per diet group), on a GC as described in detail by Sissener $e t a l .{ }^{(25)}$, based on Laakso ${ }^{(26)}$. HPLC was used for determination of tocopherols in the oils according to $\mathrm{CEN}^{(27)}$, with two analytical parallels. Phylloquinone (vitamin $\mathrm{K}_{1}$ ), menaquinone (MK4-10, $\mathrm{K}_{2}$ ) and menadione $\left(\mathrm{K}_{3}\right)$ were analysed both in the oils and feed samples with four analytical parallels by HPLC as described by Graff $e t a l{ }^{(28)}$

\section{Enzyme activities in the liver from fish reared at $12^{\circ} \mathrm{C}$}

Livers were frozen separately in liquid $\mathrm{N}_{2}$ and subsequently analysed for the activities of catalase, glutathione peroxidase and superoxide dismutase. The activity of catalase was measured according to a method described in Baudhuin et al. ${ }^{(29)}$. Superoxide dismutase activity colorimetric assay kit (Biovision) and glutathione peroxidase assay kit (Cayman Chemicals) were used to measure the activity of the two enzymes following the manufacturers' protocol. The enzyme reactions were measured using a Spectrostar Nano plate reader from BMG LABTECH $\mathrm{GmbH}$ (Ortenberg).

\section{Liver lipidomics in the $12^{\circ} \mathrm{C}$ trial}

Liver lipids were extracted in the presence of authentic internal standards by the method of Folch et al. ${ }^{(22)}$ using chloroformmethanol $(2: 1, \mathrm{v} / \mathrm{v})$. Neutral lipid classes were separated on a solvent system consisting of petroleum ether-diethyl etheracetic acid (80:20:1). Phospholipid classes were separated using the Agilent Technologies 1100 Series LC. Each lipid class was transesterified in $1 \%$ sulphuric acid in methanol in a sealed vial under $\mathrm{N}_{2}$ atmosphere at $100^{\circ} \mathrm{C}$ for $45 \mathrm{~min}$. The resulting FA methyl esters were extracted from the mixture with hexane containing $0.05 \%$ butylated hydroxytoluene and prepared for GC by sealing the hexane extracts under $N_{2}$. FA methyl esters were separated and quantified by capillary GC (Agilent Technologies 6890 Series GC), equipped with a 30 m DB 88 capillary column (Agilent Technologies) and a flame ionisation detector. For detection of ceramides, ${ }^{2} \mathrm{H}$-labelled internal standards were added and samples were solubilised in methanol, followed by a crash extraction. A bilayer was formed with the addition of $\mathrm{KCl}$ in water, and the organic layer was removed and concentrated under $\mathrm{N}_{2}$. The extract was spun, filtered and split into two injections, one for ceramides and one for sphingosines. The extract was injected onto an Agilent C8 column connected to an Agilent 1290 Infinity LC and ABI 4000 QTRAP. The analytes were ionised via positive electrospray, and the mass spectrometer was operated in the tandem MS mode. The absolute concentration of each sphingolipid was determined by comparing the peak to that of the relevant internal standard.

\section{Liver metabolomics in the $12^{\circ} \mathrm{C}$ trial}

The metabolomics work was performed by Metabolon as previously described $^{(30,31)}$ with liver samples sampled from nine fish from each of the four diet groups. Several recovery standards were added for quality control, and samples were prepared using the automated MicroLab STAR ${ }^{\circledR}$ system from Hamilton Company. Proteins were precipitated with methanol under vigorous shaking for $2 \mathrm{~min}$ (Glen Mills GenoGrinder 2000) followed by centrifugation. The resulting extract was analysed by four different methods: two separate reverse phase/ultra-performance liquid chromatography (UPLC)-MS/MS methods with positive ion mode electrospray ionisation, analysis by reverse phase/ UPLC-MS/MS with negative ion mode electrospray ionisation and analysis by hydrophilic-interaction chromatography/ UPLC-MS/MS with negative ion mode electrospray ionisation. Samples were placed briefly on a TurboVap ${ }^{\circledR}$ (Zymark) to remove the organic solvent. The sample extract was dried before being reconstituted in solvents compatible to each of the methods, and each reconstitution solvent contained a series of standards at fixed concentrations. All methods utilised a Waters ACQUITY UPLC and a Thermo Scientific Q-Exactive high-resolution/accurate mass spectrometer interfaced with a heated electrospray ionisation source and Orbitrap mass analyser operated at 35000 mass resolution (further details can be found in the references above). Metabolites were identified by automated comparison of the ion features in the experimental samples to a reference library of chemical standard entries that included retention time, molecular weight $(\mathrm{m} / \mathrm{z})$, preferred adducts and insource fragments as well as associated MS spectra ${ }^{(32)}$.

\section{Microarray analysis of liver in the $12^{\circ} \mathrm{C}$ trial}

Liver transcriptome was analysed with Nofima's 44 k microarray Salgeno containing oligonucleotide probes to all identified genes of Atlantic salmon. Analyses included all four experimental groups with five fish per group, and total twenty arrays were used. Custom microarrays were produced by Agilent Technologies, and all reagents and equipment were purchased from the same provider. One-Color Quick Amp Labelling Kit was used for RNA amplification and labelling, and fragmentation of labelled RNA was performed with a Gene Expression Hybridization kit. After overnight hybridisation in an oven $\left(17 \mathrm{~h}, 65^{\circ} \mathrm{C}\right.$, rotation speed $\left.0.01 \mathrm{~g}\right)$, arrays were washed with Gene Expression Wash Buffers 1 and 2 and scanned with the Agilent scanner. Nofima's bioinformatics pipeline STARS was used for data processing and mining of results. The high FO group was used as reference. Differentially expressed genes were selected by lows stringency criteria that are commonly applied to feeding trials: $\log _{2}$-expression ratio $>|0.6|(1.5$-fold $)$ and $P<0.05$.

\section{Calculations}

Fish growth rate was calculated as follows, based on mean weights: 
Specific growth rate $=\left(\mathrm{e}^{(\ln W 1-\ln W 0) / t}-1\right) \times 100$,

Thermal growth coefficient $=\left(W 1^{1 / 3}-W 0^{1 / 3}\right) \times 1000 / d^{\circ}$,

where $W 0$ is start weight $(\mathrm{g}), W 1$ is final weight $(\mathrm{g}), t$ is number of days and $d^{\circ}$ is sum day degrees.

Hepatosomatic index $=$ liver weight $/$ body weight $\times 100$;

Cardiosomatic index $=$ heart weight $/$ body weight $\times 100$.

\section{Statistical analyses}

In the $16^{\circ} \mathrm{C}$ trial study, tanks were used as experimental units and differences in performance were tested by one-way ANOVA followed by post hoc comparisons using Tukey-Kramer tests. Before all analyses, the ANOVA assumptions of normality of residuals and homogeneity of variances were tested using the Shapiro-Wilk and Levene tests, respectively. All analyses were performed using NCSS 11.

In the $12^{\circ} \mathrm{C}$ trial temperature trial, tanks were used as experimental units and the chosen level of significance was $P<0.05$. Changes in growth, FA compositions and enzyme activities were analysed by one-way ANOVA and Duncan's multiple range test. The mRNA transcript abundance of metabolic relevant genes in the intestine was analysed by one-way ANOVA followed by the Tukey's honest significant difference post hoc test to detect differences within dietary groups. These statistical analyses were conducted using the software SAS (SAS Institute Inc.).

Sterol levels in fish livers were analysed by nested ANOVA, with tank as a random factor and diet as a fixed factor, conducted in Statistica (version 13.1; Statsoft). For statistical analyses of the metabolomics/lipidomics data, any missing values were assumed to be below the limits of detection and these values were imputed with the compound minimum (minimum value imputation). While the lipidomics data are quantitative, the other metabolites are given in relative quantities and for these, the raw data for each biochemical were re-scaled to have a median of 1 . Statistical analysis of log-transformed data was performed using $\mathrm{R}$ (http://cran.r-project.org/), which is a freely available, opensource software package. A two-way ANOVA with contrasts was used to identify statistically significant $(P<0.05)$ effects of oil source (DHA-CA $v$. FO), effects of inclusion level (high $v$. low) and interaction between oil source and level. Multiple comparisons were accounted for by estimating the false discovery rate $(q$-value $<0 \cdot 10)$. In the figures, the lipid metabolites and enzyme activities are displayed in Tukey box plots, showing median, upper and lower quartiles, maximum and minimum of distributions, while outlier data points are indicated by a triangle.

\section{Results}

\section{Characterisation of n-3-rich modified canola oil and} control canola oil

There were major differences in the FA composition of the dietary oils DHA-CA $v$. Ctr-CA, with lower levels of $18: 1 n-9$ (39) v. 64\%) and 18:2n-6 (9 v. 13\%) and higher levels of
$18: 3 n-3$ (21 v. 13\%) and $22: 6 n-3$ (8.2 v. 0\%) occurring in the DHA-CA than in the Ctr-CA, respectively (Table 3 ). The DHA-CA also contained 0.4\% 20:5n-3 and 0.8\% 22:5n-3. In addition, the DHA-CA had a higher level of total vitamin $\mathrm{E}$ forms compared with the Ctr-CA, which was primarily due to an increased level of $\boldsymbol{\gamma}$-tocopherol, with values of $325 \mathrm{mg} / \mathrm{kg}$ in the DHA-CA compared with $282 \mathrm{mg} / \mathrm{kg}$ in the Ctr-CA.

A range of undesirables were analysed in the two canola oils, and of the 119 organophosphate pesticides, the thirty chlorinated pesticides and heavy metals, all were below limit of quantification in both oils (data not shown). Only compounds often detected in commercial oils above the limit of quantification are shown in Table 3. In general, the undesirables normally detected in canola oils used in commercial fish feeds were not detected or were below limit of quantification in the two canola oils (DHA-CA and Ctr-CA) used in the current feeding trials. The profile of individual phytosterols differed, with a lower proportion of brassicasterol occurring in the phytosterols in the DHA-CA than in Ctr-CA.

The total content of vitamin $\mathrm{K}$ was higher in the DHA-CA with $3.6 \mathrm{mg} / \mathrm{kg}$, compared with $1.6 \mathrm{mg} / \mathrm{kg}$ in the Ctr-CA. In the oils, $0 \cdot 0-0 \cdot 1 \%$ of total vitamin $\mathrm{K}$ was $\mathrm{K}_{3}$, while the remainder was $\mathrm{K}_{1}$ (approximately $95 \%$ trans- $\mathrm{K}_{1}$ and approximately $5 \%$ cis- $\mathrm{K}_{1}$ ).

\section{Composition of fish feeds}

Table 4 shows the FA composition of the diets used in the two temperature trials. When exchanging FO with DHA-CA, the typical plant FA $18: 1 n-9$ and $18: 2 n-6$ remained relatively similar between the comparable diet groups, but the total SFA was reduced compared with the level of these FA in the corresponding FO diets, while the levels of $18: 3 n-3$ increased. The sum of $\mathrm{EPA}+\mathrm{DHA}$ was similar in the two comparable diets (Low FO $v$. Low DHA-CA and High FO $v$. High DHA-CA), but due to the fact that the DHA-CA oil mainly contains DHA and less EPA, the DHA-CA diets contained slightly more DHA and less EPA than the corresponding FO diets. There were some differences between the diets for the two temperature trials; in general, the EPA+DHA and SFA were higher and the MUFA and n-6 PUFA were lower in the diets for the $16^{\circ} \mathrm{C}$ trial compared with the level of these in the diets for the $12^{\circ} \mathrm{C}$ trial due to different sources of the ingredients FM and FO.

\section{Fish performance and whole-body composition}

The fish at $16^{\circ} \mathrm{C}$ grew from an initial weight of $0.8 \mathrm{~g}$ to a final weight of approximately $15.5 \mathrm{~g}$, while fish in the $12^{\circ} \mathrm{C}$ trial grew from 2 to $24 \mathrm{~g}$, resulting in an approximately 20 -fold increase in weight during the course of the trial at $16^{\circ} \mathrm{C}$ and an approximately 12 -fold increase at $12^{\circ} \mathrm{C}$ (Table 5 ). The specific growth rate at $16^{\circ} \mathrm{C}$ was $40 \%$ higher than that at $12^{\circ} \mathrm{C}$. There was no difference in specific growth rate or thermal growth coefficient between the dietary groups within each temperature trial. Survival was very high ( $\geq 94 \%)$ in all groups.

There were also no differences in proximate whole-body composition (protein, DM and ash) and energy content of fish in the different experimental groups in either of the experiments (Table 6). However, when salmon were reared at $16^{\circ} \mathrm{C}$, the wholebody lipid content was significantly increased in fish fed diets containing the DHA-CA oil compared with those fed the FO-diets. 
Table 4. Fatty acid composition (\% of total fatty acids) of the experimental feeds

\begin{tabular}{|c|c|c|c|c|c|c|c|c|}
\hline & \multicolumn{4}{|c|}{$16^{\circ} \mathrm{C}$ water temperature trial } & \multicolumn{4}{|c|}{$12^{\circ} \mathrm{C}$ water temperature trial } \\
\hline & Low FO & High FO & Low DHA-CA & High DHA-CA & Low FO & High FO & Low DHA-CA & High DHA-CA \\
\hline $14: 0$ & $4 \cdot 1$ & $4 \cdot 5$ & $3 \cdot 7$ & $3 \cdot 7$ & $3 \cdot 7$ & $4 \cdot 3$ & $3 \cdot 1$ & $3 \cdot 2$ \\
\hline $16: 0$ & $16 \cdot 4$ & $18 \cdot 4$ & $14 \cdot 8$ & $15 \cdot 0$ & $11 \cdot 2$ & $12 \cdot 2$ & $10 \cdot 4$ & $10 \cdot 6$ \\
\hline $18: 0$ & $3 \cdot 4$ & $3 \cdot 9$ & $3 \cdot 2$ & $3 \cdot 3$ & 1.9 & $2 \cdot 1$ & $2 \cdot 0$ & $2 \cdot 0$ \\
\hline $20: 0$ & 0.3 & 0.3 & 0.3 & $0 \cdot 2$ & 0.3 & 0.3 & 0.4 & 0.4 \\
\hline$\Sigma$ SFA $^{*}$ & $27 \cdot 2$ & $30 \cdot 5$ & 23.9 & 23.5 & $17 \cdot 7$ & $19 \cdot 7$ & $16 \cdot 6$ & $16 \cdot 8$ \\
\hline $16: 1 n-7$ & $4 \cdot 3$ & $4 \cdot 8$ & $3 \cdot 8$ & 3.9 & $2 \cdot 6$ & $3 \cdot 1$ & $2 \cdot 0$ & $2 \cdot 1$ \\
\hline $18: 1 n-7$ & 3.0 & 3.0 & 3.0 & 3.0 & 2.7 & 2.5 & 3.0 & $3 \cdot 2$ \\
\hline $18: 1 n-9$ & 34.2 & $28 \cdot 8$ & 32.9 & $26 \cdot 7$ & $29 \cdot 8$ & 23.6 & $29 \cdot 7$ & $24 \cdot 2$ \\
\hline $20: 1 n-9$ & 1.6 & 1.6 & 1.6 & 1.6 & $5 \cdot 8$ & $6 \cdot 3$ & $5 \cdot 0$ & $5 \cdot 1$ \\
\hline $22: 1 n-11$ & nd & nd & nd & nd & $9 \cdot 2$ & $10 \cdot 3$ & $7 \cdot 7$ & $7 \cdot 8$ \\
\hline$\Sigma$ MUFA† & 44.0 & 39.0 & $42 \cdot 1$ & 35.9 & $52 \cdot 2$ & $49 \cdot 1$ & $49 \cdot 8$ & $44 \cdot 8$ \\
\hline $18: 2 n-6$ & $7 \cdot 7$ & $6 \cdot 7$ & $7 \cdot 8$ & 7 & 6.5 & $5 \cdot 2$ & $6 \cdot 6$ & $5 \cdot 7$ \\
\hline $20: 4 n-6$ & 0.5 & 0.6 & 0.3 & 0.3 & 0.3 & 0.4 & 0.3 & 0.3 \\
\hline$\Sigma n-6 \ddagger$ & 8.5 & 8.0 & 8.5 & 8.0 & $7 \cdot 1$ & 5.9 & $7 \cdot 4$ & 6.6 \\
\hline $18: 3 n-3$ & 4.0 & $3 \cdot 3$ & $7 \cdot 8$ & 10.9 & 4.4 & 3.4 & $7 \cdot 8$ & $10 \cdot 2$ \\
\hline $18: 4 n-3$ & $1 \cdot 1$ & $1 \cdot 2$ & 1.6 & $2 \cdot 2$ & 0.2 & 0.2 & 0.2 & 0.2 \\
\hline $20: 4 n-3$ & 0.3 & 0.3 & 0.5 & 0.9 & 1.4 & $1 \cdot 8$ & 1.4 & $1 \cdot 8$ \\
\hline $20: 5 n-3$ & $7 \cdot 0$ & 7.5 & 6.7 & $6 \cdot 8$ & 5.0 & $6 \cdot 2$ & 3.9 & 4.0 \\
\hline $22: 5 n-3$ & 0.2 & 0.2 & 1.0 & 1.7 & 0.6 & 0.7 & 0.7 & 0.8 \\
\hline $22: 6 n-3$ & $7 \cdot 5$ & 9.9 & $7 \cdot 4$ & 9.6 & $8 \cdot 1$ & 8.7 & 9.0 & $11 \cdot 0$ \\
\hline$\sum n-3 \S$ & $22 \cdot 4$ & $25 \cdot 0$ & $27 \cdot 7$ & 34.8 & $19 \cdot 7$ & 20.9 & $23 \cdot 2$ & $28 \cdot 4$ \\
\hline $\mathrm{EPA}+\mathrm{DHA}$ & $17 \cdot 0$ & $20 \cdot 5$ & $17 \cdot 0$ & $19 \cdot 4$ & $13 \cdot 1$ & 14.9 & $13 \cdot 0$ & $15 \cdot 0$ \\
\hline
\end{tabular}

FA profiles in the whole body of fish from the two temperature experiments are presented in Table 7. In general, for both trials, the percentages of SFA were lower and the total $n$ - 3 FA were higher in both the DHA-CA groups than in the FO groups, reflecting the high $18: 3 n-3$ content and the lower SFA contents of these diets. The two Low dietary groups (Low FO $v$. Low DHA$\mathrm{CA}$ ) and the two High dietary groups (High FO $v$. High DHA-CA) had similar percentages of EPA+DHA in whole body in both trials, although the actual level was higher in the low-temperature trial due to the higher level occurring in their diets.

\section{Fat content and fatty acid compositions of erythrocytes and muscle in fish in the $12^{\circ} \mathrm{C}$ trial}

There were no significant differences in total lipid content in muscle between the dietary groups, with the lipid content (\% of wet weight) of approximately $5 \%$ in all dietary groups (Table 8). The total FA composition of the muscle showed only minor differences in the percentage of SFA (approximately $21 \%$ of total FA) between the groups. The percentages of MUFA and total $n$ - 6 FA were mostly affected by the inclusion level of the oils and only moderately by the oil source. Thus, slightly lower percentages of MUFA (approximately $41 v .43 \%$ ) and of $n-6$ FA (approximately $5.4 v .6 \cdot 0 \%$ ) were observed in the muscle from the High groups compared with those in the Low groups. The opposite result was found for the content of total $n-3$ FA, where the two High dietary groups had the highest percentages of $n$-3 FA (approximately $29 v .27 \%$ ). The percentage of EPA was lower in the muscle of the two groups fed the DHA-CA diets compared with the FO diets, while $18: 3 n-3$ and DHA were higher. The two Low dietary groups (Low FO $v$. Low DHA-CA) had approximately $22 \%$, and the two High dietary groups (High FO $v$. High DHA-CA) had approximately 24 and $22 \%$, respectively, of $\mathrm{EPA}+\mathrm{DHA}$ in muscle, showing that the EPA+DHA from the DHA-CA oil was incorporated into muscle tissue to approximately the same extent as from FO.

Total lipid content of erythrocytes was similar in all dietary groups (Table 9). The percentages of SFA were in general higher in the FO groups than in the two DHA-CA groups, while the MUFA and total $n-6$ FA were similar in all diet groups. The total $n$-3 FA were lower in the FO groups relative to their corresponding DHA-CA groups (Low FO $v$. Low DHA-CA and High FO $v$. High DHA-CA). The increase in total $n-3$ FA was due to the higher content of $18: 3 n-3$ in the erythrocytes from fish fed the DHA-CA diets. Erythrocytes' EPA content was higher in the FO groups than the DHA-CA groups due to a higher content of EPA in the FO diets. However, there was no significant difference in DHA content in erythrocytes of the different groups.

\section{Liver responses in the fish reared at $12^{\circ} \mathrm{C}$ : liver lipids, metabolomics, markers for oxidative stress and transcriptome analysis}

Liver lipids were analysed both by traditional methods for total lipid, total FA profile and sterol content (Table 10), as well as by lipidomic analysis, the later providing quantitation of the total TAG (Fig. 1) and determination of how the dietary FA are influencing the FA composition of different polar and neutral lipid classes (Fig. 2). Table 10 shows that there were no significant differences in total lipid content in liver between the dietary groups. The lipid content (\% of wet weight) was $5.8 \%$ in the High DHA-CA and approximately $6.3 \%$ in the other dietary 
Table 5. Growth and survival over the experimental period*

(Mean values using tank as a statistical unit $(n 3)$ with their standard errors)

\begin{tabular}{|c|c|c|c|c|c|c|c|c|c|c|c|c|c|c|c|c|c|c|}
\hline & \multicolumn{8}{|c|}{$16^{\circ} \mathrm{C}$ water temperature trial } & \multicolumn{9}{|c|}{$12^{\circ} \mathrm{C}$ water temperature trial } & \multirow[b]{3}{*}{ ANOVA, $P$} \\
\hline & \multicolumn{2}{|c|}{ Low FO } & \multicolumn{2}{|c|}{ High FO } & \multicolumn{2}{|c|}{ Low DHA-CA } & \multicolumn{2}{|c|}{ High DHA-CA } & \multirow[b]{2}{*}{ ANOVA, $P$} & \multicolumn{2}{|c|}{ Low FO } & \multicolumn{2}{|c|}{ High FO } & \multicolumn{2}{|c|}{ Low DHA-CA } & \multicolumn{2}{|c|}{ High DHA-CA } & \\
\hline & Mean & SE & Mean & SE & Mean & $\mathrm{SE}$ & Mean & SE & & Mean & SE & Mean & $\mathrm{SE}$ & Mean & SE & Mean & $\mathrm{SE}$ & \\
\hline \multicolumn{19}{|l|}{ Body weight (g) } \\
\hline Day 0 & 0.83 & 0.01 & 0.84 & 0.02 & 0.86 & 0.03 & 0.83 & 0.02 & 0.74 & 2.04 & 0.09 & $2 \cdot 16$ & 0.04 & 2.08 & 0.04 & 2.05 & 0.01 & 0.46 \\
\hline Period 1 & 4.63 & 0.12 & 4.49 & 0.06 & 4.49 & 0.14 & 4.44 & 0.13 & 0.68 & 4.47 & 0.19 & 4.79 & 0.07 & 4.52 & 0.10 & 4.38 & 0.03 & 0.14 \\
\hline Period 2 & $10 \cdot 35$ & 0.08 & $10 \cdot 14$ & 0.28 & $10 \cdot 17$ & 0.09 & 9.94 & 0.20 & 0.48 & 6.82 & 0.29 & 7.33 & $0 \cdot 10$ & 6.81 & 0.16 & 6.67 & 0.03 & 0.11 \\
\hline Period 3 & $15 \cdot 49$ & 0.47 & $15 \cdot 29$ & 0.31 & $16 \cdot 22$ & 0.77 & $15 \cdot 25$ & 0.22 & 0.47 & 23.82 & 0.94 & $25 \cdot 41$ & 0.80 & $23 \cdot 28$ & 0.62 & 23.74 & 1.02 & 0.38 \\
\hline \multicolumn{19}{|l|}{ SGR $(\% / d)$} \\
\hline Period 1 & 5.04 & 0.09 & 4.94 & 0.02 & 4.90 & 0.04 & 4.94 & 0.03 & 0.18 & 2.95 & 0.03 & 3.01 & 0.12 & 2.93 & 0.07 & 2.87 & 0.03 & 0.64 \\
\hline Period 2 & 3.66 & 0.08 & 3.72 & 0.05 & 3.73 & $0 \cdot 10$ & 3.67 & 0.06 & 0.90 & 3.05 & 0.03 & 3.08 & 0.03 & 2.97 & 0.07 & 3.03 & 0.08 & 0.57 \\
\hline Period 3 & 2.87 & 0.26 & 2.91 & 0.12 & 3.18 & 0.20 & 3.06 & 0.04 & 0.65 & 3.02 & 0.03 & 3.00 & 0.05 & 2.97 & 0.01 & 3.07 & 0.11 & 0.73 \\
\hline SGR total & 4.17 & 0.04 & 4.20 & 0.02 & $4 \cdot 20$ & 0.02 & $4 \cdot 16$ & 0.02 & 0.72 & 3.01 & 0.01 & 3.02 & 0.07 & 2.96 & 0.02 & 3.00 & 0.04 & 0.76 \\
\hline TGC total & 1.36 & 0.02 & 1.35 & 0.01 & 1.38 & 0.027 & 1.35 & 0.00 & 0.73 & 1.59 & 0.02 & 1.63 & 0.04 & 1.57 & 0.02 & 1.59 & 0.04 & 0.50 \\
\hline Survival (\%) & 99.7 & 0.40 & 99.0 & 0.40 & 98.0 & 0.49 & 99.3 & 0.40 & 0.14 & $97 \cdot 2$ & $1 \cdot 2$ & 97.0 & 1.5 & $96 \cdot 7$ & 1.4 & 93.7 & 3.0 & 0.55 \\
\hline
\end{tabular}

FO, fish oil; DHA-CA, $n$-3-rich modified canola oil; SGR, specific growth rate; TGC, thermal growth coefficient.

*The period from 0 to $34 \mathrm{~d}$ is denoted Period 1 , from 34 to $56 \mathrm{~d}$ is denoted Period 2 and from d 56 to $70 \mathrm{~d}$ is denoted Period 3 in the $16^{\circ} \mathrm{C}$ trial. The period from 0 to $27 \mathrm{~d}$ is denoted Period 1 , from 27 to $41 \mathrm{~d}$ is denoted Period 2 and from $\mathrm{d} 41$ to $83 \mathrm{~d}$ is denoted Period 3 in the $12^{\circ} \mathrm{C}$ trial.

Table 6. Proximate composition and energy content of whole fish at the end of the experiment

(Mean values using tank as a statistical unit ( $n 3$, being each sample represented by a pool of five fish) with their standard errors)

\begin{tabular}{|c|c|c|c|c|c|c|c|c|c|c|c|c|c|c|c|c|c|c|}
\hline & \multicolumn{8}{|c|}{$16^{\circ} \mathrm{C}$ water temperature trial } & \multicolumn{9}{|c|}{$12^{\circ} \mathrm{C}$ water temperature trial } & \multirow[b]{3}{*}{ ANOVA, $P$} \\
\hline & \multicolumn{2}{|c|}{ Low FO } & \multicolumn{2}{|c|}{ High FO } & \multicolumn{2}{|c|}{ Low DHA-CA } & \multicolumn{2}{|c|}{ High DHA-CA } & \multirow[b]{2}{*}{ ANOVA, $P$} & \multicolumn{2}{|c|}{ Low FO } & \multicolumn{2}{|c|}{ High FO } & \multicolumn{2}{|c|}{ Low DHA-CA } & \multicolumn{2}{|c|}{ High DHA-CA } & \\
\hline & Mean & SE & Mean & SE & Mean & SE & Mean & SE & & Mean & SE & Mean & SE & Mean & SE & Mean & SE & \\
\hline DM & $25 \cdot 9$ & 0.55 & $25 \cdot 8$ & 0.66 & $27 \cdot 3$ & 0.3 & $27 \cdot 3$ & 0.20 & 0.09 & $27 \cdot 2$ & 0.36 & $27 \cdot 6$ & 0.15 & $27 \cdot 1$ & 0.06 & $27 \cdot 2$ & 0.18 & 0.43 \\
\hline Protein & $15 \cdot 3$ & 0.36 & $15 \cdot 6$ & 0.61 & $16 \cdot 2$ & 0.22 & $15 \cdot 8$ & 0.17 & 0.6 & $16 \cdot 1$ & 0.05 & $16 \cdot 2$ & 0.07 & $16 \cdot 4$ & 0.19 & $16 \cdot 1$ & 0.07 & 0.16 \\
\hline Lipid & $9 \cdot 6^{a}$ & 0.31 & $9 \cdot 5^{a}$ & 0.13 & $10 \cdot 6^{b}$ & 0.28 & $10.9^{b}$ & 0.40 & 0.03 & $10 \cdot 7$ & 0.53 & $11 \cdot 0$ & 0.15 & $10 \cdot 4$ & 0.07 & $10 \cdot 4$ & 0.09 & 0.44 \\
\hline Ash & 1.6 & 0.07 & 1.6 & 0.09 & 1.5 & 0.08 & 1.6 & 0.07 & 0.87 & 2.4 & 0.06 & $2 \cdot 4$ & 0.06 & 2.4 & 0.15 & $2 \cdot 3$ & 0.06 & 0.74 \\
\hline Energy (MJ/kg) & $7 \cdot 18$ & 0.15 & $7 \cdot 16$ & 0.19 & 7.56 & 0.19 & $7 \cdot 76$ & $0 \cdot 16$ & $0 \cdot 10$ & $7 \cdot 27$ & 0.12 & 7.52 & 0.03 & $7 \cdot 21$ & 0.05 & $7 \cdot 25$ & 0.05 & 0.06 \\
\hline
\end{tabular}

FO, fish oil; DHA-CA, $n$-3-rich modified canola oil.

a,b Mean values within a row with unlike superscript letters were significantly different $(P<0.05)$. 
Table 7. Fatty acid composition (\% of total) in the whole body of Atlantic salmon fed the experimental diets for $70 \mathrm{~d}$ at high $\left(16^{\circ} \mathrm{C}\right)$ and for $83 \mathrm{~d}$ at low $\left(12^{\circ} \mathrm{C}\right)$ water temperature (Mean values using tank as a statistical unit ( $n 3$, being each sample represented by a pool of five fish) with their standard errors)

\begin{tabular}{|c|c|c|c|c|c|c|c|c|c|c|c|c|c|c|c|c|c|c|}
\hline & \multicolumn{8}{|c|}{$16^{\circ} \mathrm{C}$ water temperature trial } & \multirow[b]{3}{*}{ ANOVA, $P$} & \multicolumn{8}{|c|}{$12^{\circ} \mathrm{C}$ water temperature trial } & \multirow[b]{3}{*}{ ANOVA, $P$} \\
\hline & \multicolumn{2}{|c|}{ Low FO } & \multicolumn{2}{|c|}{ High FO } & \multicolumn{2}{|c|}{ Low DHA-CA } & \multicolumn{2}{|c|}{ High DHA-CA } & & \multicolumn{2}{|c|}{ Low FO } & \multicolumn{2}{|c|}{ High FO } & \multicolumn{2}{|c|}{ Low DHA-CA } & \multicolumn{2}{|c|}{ High DHA-CA } & \\
\hline & Mean & $\mathrm{SE}$ & Mean & SE & Mean & SE & Mean & SE & & Mean & $\mathrm{SE}$ & Mean & $\mathrm{SE}$ & Mean & SE & Mean & $\mathrm{SE}$ & \\
\hline $14: 0$ & $3 \cdot 7^{\mathrm{a}}$ & 0.02 & $4.05^{b}$ & 0.03 & $3 \cdot 4^{\mathrm{c}}$ & 0.03 & $3.5^{\mathrm{c}}$ & 0.02 & $<0.001$ & $3.4^{b}$ & 0.03 & $3.9^{a}$ & 0.09 & $3.0^{c}$ & 0.03 & $3.0^{c}$ & 0.03 & $<0.0001$ \\
\hline $16: 0$ & $17 \cdot 0^{\mathrm{a}}$ & 0.13 & $18 \cdot 5^{\mathrm{b}}$ & 0.17 & $15 \cdot 8^{c}$ & 0.10 & $16.0^{c}$ & 0.12 & $<0.0001$ & $13.0^{\mathrm{b}}$ & 0.03 & $13 \cdot 7^{a}$ & 0.03 & $12 \cdot 2^{c}$ & 0.23 & $12 \cdot 1^{\mathrm{c}}$ & 0.03 & $<0.0001$ \\
\hline $18: 0$ & $4 \cdot 3^{\mathrm{a}}$ & 0.05 & $4.7^{\mathrm{b}}$ & 0.01 & $4 \cdot 2^{a}$ & 0.01 & $4 \cdot 3^{\mathrm{a}}$ & 0.05 & $<0.001$ & 2.9 & 0.03 & 2.9 & 0.03 & 2.9 & 0.03 & 3.0 & 0.03 & 0.44 \\
\hline $20: 0$ & $0.3^{\mathrm{a}}$ & 0.00 & $0.3^{b}$ & 0.00 & $0.3^{a}$ & 0.00 & $0.3^{\mathrm{a}}$ & 0.00 & $<0.001$ & 0.3 & 0.00 & 0.3 & 0.03 & 0.3 & 0.03 & 0.3 & 0.00 & 0.33 \\
\hline$\Sigma \mathrm{SFA}^{*}$ & $26 \cdot 3^{\mathrm{a}}$ & 0.18 & $28 \cdot 8^{\mathrm{b}}$ & 0.22 & $24.8^{c}$ & 0.20 & $25 \cdot 1^{c}$ & 0.13 & $<0.0001$ & $20.0^{\mathrm{b}}$ & 0.06 & $21 \cdot 3^{\mathrm{a}}$ & 0.13 & $18 \cdot 9^{c}$ & 0.30 & $19 \cdot 0^{\mathrm{C}}$ & 0.07 & $<0.0001$ \\
\hline $16: 1 n-7$ & $4.0^{\mathrm{a}}$ & 0.05 & $4.5^{\mathrm{b}}$ & 0.03 & $3.7^{c}$ & 0.03 & $3.7^{c}$ & 0.01 & $<0.0001$ & $3 \cdot 2^{b}$ & 0.15 & $3 \cdot 6^{a}$ & $0 \cdot 10$ & $2 \cdot 3^{c}$ & 0.09 & $2 \cdot 2^{\mathrm{C}}$ & 0.00 & $<0.0001$ \\
\hline $18: 1 n-7$ & $3 \cdot 4^{\mathrm{a}}$ & 0.01 & $3 \cdot 4^{a}$ & 0.01 & $3.3^{b}$ & 0.02 & $3.3^{\mathrm{b}}$ & 0.01 & $<0.01$ & $3.7^{c}$ & 0.07 & $3 \cdot 6^{c}$ & 0.00 & $4 \cdot 0^{\mathrm{b}}$ & 0.03 & $4 \cdot 3^{\mathrm{a}}$ & 0.03 & $<0.0001$ \\
\hline $18: 1 n-9$ & $34.9^{\mathrm{a}}$ & 0.16 & $30 \cdot 3^{b}$ & 0.20 & $34.0^{c}$ & 0.07 & $28 \cdot 2^{d}$ & 0.09 & $<0.0001$ & $31.6^{a}$ & 0.20 & $26 \cdot 7^{\mathrm{b}}$ & 0.20 & $31 \cdot 3^{\mathrm{a}}$ & 0.12 & $26 \cdot 2^{\mathrm{b}}$ & 0.07 & $<0.0001$ \\
\hline $20: 1 n-9$ & $2 \cdot 4^{\mathrm{a}}$ & 0.01 & $2 \cdot 2^{\mathrm{b}}$ & 0.03 & $2 \cdot 3^{c}$ & 0.03 & $2 \cdot 1^{d}$ & 0.00 & $<0.0001$ & $6 \cdot 3^{\mathrm{b}}$ & 0.06 & $6 \cdot 8^{a}$ & 0.03 & $5 \cdot 6^{\mathrm{c}}$ & 0.03 & $5 \cdot 4^{d}$ & 0.00 & $<0.0001$ \\
\hline $22: 1 n-11$ & nd & & nd & & nd & & nd & & & $6 \cdot 1^{\mathrm{a}}$ & 0.06 & $6 \cdot 5^{\mathrm{a}}$ & 0.24 & $4 \cdot 8^{\mathrm{b}}$ & 0.24 & $5 \cdot 3^{b}$ & 0.06 & 0.0005 \\
\hline$\Sigma$ MUFA† & $45 \cdot 7^{\mathrm{a}}$ & 0.17 & 41.4 & 0.252 & $44 \cdot 2^{c}$ & 0.11 & $38.1^{d}$ & 0.09 & $<0.0001$ & $54.0^{\mathrm{a}}$ & 0.23 & $51 \cdot 3^{b}$ & 0.26 & $51.9^{b}$ & 0.18 & $47 \cdot 8^{c}$ & 0.09 & $<0.0001$ \\
\hline $18: 2 n-6$ & $6 \cdot 4^{\mathrm{a}}$ & 0.05 & $5.7^{b}$ & 0.03 & $6 \cdot 4^{a}$ & 0.03 & $5 \cdot 9^{c}$ & 0.07 & $<0.0001$ & $5 \cdot 4^{\mathrm{a}}$ & 0.06 & $4 \cdot 5^{c}$ & 0.00 & $5 \cdot 5^{a}$ & 0.10 & $4 \cdot 9^{b}$ & 0.00 & $<0.0001$ \\
\hline $20: 4 n-6$ & $0.5^{\mathrm{a}}$ & 0.01 & $0.6^{\mathrm{b}}$ & 0.01 & $0.3^{c}$ & 0.01 & $0.3^{c}$ & 0.01 & $<0.0001$ & 0.3 & 0.00 & 0.3 & 0.00 & 0.3 & 0.00 & 0.3 & 0.00 & \\
\hline$\sum n-6 \ddagger$ & $7 \cdot 8^{\mathrm{a}}$ & 0.06 & $7 \cdot 3^{\mathrm{b}}$ & 0.11 & $7 \cdot 6^{\mathrm{a}}$ & 0.03 & $7 \cdot 1^{\mathrm{b}}$ & 0.11 & $<0.0001$ & $6 \cdot 8^{\mathrm{a}}$ & 0.03 & $5 \cdot 9^{c}$ & 0.09 & $6 \cdot 9^{\mathrm{a}}$ & 0.09 & $6 \cdot 4^{\mathrm{b}}$ & 0.03 & $<0.0001$ \\
\hline $18: 3 n-3$ & $3 \cdot 1^{\mathrm{a}}$ & 0.05 & $2 \cdot 6^{\mathrm{b}}$ & 0.06 & $5 \cdot 9^{c}$ & 0.02 & $8.5^{\mathrm{d}}$ & 0.12 & $<0.0001$ & $3 \cdot 2^{c}$ & 0.06 & $2 \cdot 6^{d}$ & 0.00 & $5 \cdot 7^{\mathrm{b}}$ & 0.10 & $7 \cdot 8^{\mathrm{a}}$ & 0.03 & $<0.0001$ \\
\hline $18: 4 n-3$ & $0.9^{a}$ & 0.01 & $0.9^{\mathrm{a}}$ & 0.01 & $1.3^{b}$ & 0.01 & $1.8^{\mathrm{c}}$ & 0.03 & $<0.0001$ & nd & & nd & & nd & & nd & & \\
\hline $20: 3 n-3$ & $0.2^{\mathrm{a}}$ & 0.00 & $0.2^{\mathrm{b}}$ & 0.00 & $0.5^{\mathrm{c}}$ & 0.00 & $0.7^{d}$ & 0.00 & $<0.0001$ & $0.2^{\mathrm{b}}$ & 0.00 & $0.2^{\mathrm{b}}$ & 0.00 & $0.5^{\mathrm{a}}$ & 0.03 & $0.6^{\mathrm{a}}$ & 0.12 & 0.003 \\
\hline $20: 4 n-3$ & $0.5^{\mathrm{a}}$ & 0.00 & $0.5^{\mathrm{a}}$ & 0.01 & $0.8^{b}$ & 0.00 & $1 \cdot 2^{c}$ & 0.00 & $<0.001$ & $0.6^{\mathrm{b}}$ & 0.09 & $0.8^{a}$ & 0.01 & $0.6^{\mathrm{b}}$ & 0.01 & $0.6^{\mathrm{b}}$ & 0.00 & 0.02 \\
\hline $20: 5 n-3$ & $3 \cdot 0^{\mathrm{a}}$ & 0.05 & $3 \cdot 2^{b}$ & 0.03 & $2 \cdot 9^{\mathrm{a}}$ & 0.02 & $3 \cdot 2^{c}$ & 0.04 & $<0.0001$ & $2 \cdot 8^{\mathrm{b}}$ & 0.00 & $3.5^{\mathrm{a}}$ & 0.03 & $2 \cdot 4^{c}$ & 0.00 & $2 \cdot 5^{\mathrm{c}}$ & 0.03 & $<0.0001$ \\
\hline $22: 5 n-3$ & 1.4 & 0.00 & 1.5 & 0.02 & $1 \cdot 2$ & 0.21 & 1.4 & 0.23 & 0.55 & $0.9^{b}$ & 0.03 & $1 \cdot 2^{\mathrm{a}}$ & 0.00 & $0.9^{b}$ & 0.03 & $0.9^{b}$ & 0.03 & 0.0002 \\
\hline $22: 6 n-3$ & $11.0^{\mathrm{a}}$ & 0.16 & $13 \cdot 1^{\mathrm{b}}$ & 0.15 & $10 \cdot 7^{a}$ & 0.05 & $12 \cdot 8^{\mathrm{b}}$ & 0.10 & $<0.0001$ & $9.7^{d}$ & 0.19 & $10 \cdot 8^{\mathrm{b}}$ & 0.07 & $10 \cdot 4^{c}$ & 0.12 & $12 \cdot 2^{\mathrm{a}}$ & 0.03 & $<0.0001$ \\
\hline$\Sigma n-3$ & $20.5^{\mathrm{a}}$ & 0.26 & $22 \cdot 6^{\mathrm{b}}$ & 0.22 & $23 \cdot 7^{b}$ & 0.23 & $29 \cdot 9^{c}$ & 0.09 & $<0.0001$ & $17 \cdot 6^{\mathrm{d}}$ & 0.15 & $19 \cdot 3^{c}$ & 0.20 & $20 \cdot 6^{\mathrm{b}}$ & 0.23 & $24.7^{a}$ & 0.17 & $<0.0001$ \\
\hline$n-6: n-3$ & $0.38^{a}$ & 0.00 & $0.32^{\mathrm{b}}$ & 0.00 & $0.32^{b}$ & 0.00 & $0.24^{c}$ & 0.00 & $<0.001$ & $0.38^{a}$ & 0.00 & $0.31^{\mathrm{c}}$ & 0.00 & $0.33^{b}$ & 0.01 & $0.26^{\mathrm{d}}$ & 0.00 & $<0.0001$ \\
\hline $\mathrm{EPA}+\mathrm{DHA}$ & $17 \cdot 1^{\mathrm{a}}$ & 0.25 & $20 \cdot 1^{\mathrm{b}}$ & 0.20 & $16 \cdot 6^{\mathrm{a}}$ & 0.08 & $19.6^{\mathrm{b}}$ & 0.15 & $<0.0001$ & $12 \cdot 5^{\mathrm{b}}$ & 0.19 & $14 \cdot 3^{a}$ & 0.10 & $12 \cdot 8^{\mathrm{b}}$ & 0.12 & $14 \cdot 7^{\mathrm{a}}$ & 0.06 & $<0.0001$ \\
\hline
\end{tabular}

FO, fish oil; DHA-CA, $n$-3-rich modified canola oil; nd, not determined.

a,b,c,d Mean values within a row with unlike superscript letters were significantly different $(P<0.05)$

* Includes 15:0,17:0,19:0 and 21:0.

† Includes 17:1, 20:1n-7, 20:1n-11, 22:1n-7, $22: 1 n-9$ and $24: 1 n-9$.

$\neq$ Includes $18: 3 n-6,20: 2 n-6,20: 3 n-6$ and $22: 4 n-6$. 
Table 8. Lipid content (\% of wet weight) and fatty acid composition (\% of total) in the muscle of Atlantic salmon fed the experimental diets for $83 \mathrm{~d}$ at low $\left(12^{\circ} \mathrm{C}\right)$ water temperature

(Mean values using tank as a statistical unit ( $n 3$, being each sample represented by a pool of five fish) with their standard errors)

\begin{tabular}{|c|c|c|c|c|c|c|c|c|c|}
\hline & \multicolumn{2}{|c|}{ Low FO } & \multicolumn{2}{|c|}{ High FO } & \multicolumn{2}{|c|}{ Low DHA-CA } & \multicolumn{2}{|c|}{ High DHA-CA } & \multirow[b]{2}{*}{ ANOVA, $P$} \\
\hline & Mean & SE & Mean & SE & Mean & SE & Mean & SE & \\
\hline Total fat & $5 \cdot 0$ & 0.14 & $5 \cdot 3$ & 0.18 & $4 \cdot 7$ & 0.32 & 5.5 & 0.20 & 0.12 \\
\hline $14: 0$ & $3.4^{\mathrm{b}}$ & 0.02 & $3.8^{a}$ & 0.02 & $3.1^{c}$ & 0.17 & $2 \cdot 9^{c}$ & 0.01 & 0.0004 \\
\hline $16: 0$ & $13 \cdot 7^{\mathrm{a}, \mathrm{b}}$ & 0.07 & $14 \cdot 2^{\mathrm{a}}$ & 0.22 & $13 \cdot 2^{b}$ & 0.29 & $13 \cdot 1^{b}$ & 0.06 & 0.01 \\
\hline $18: 0$ & $2 \cdot 7$ & 0.04 & $2 \cdot 6$ & 0.39 & $2 \cdot 7$ & 0.03 & $2 \cdot 9$ & 0.06 & $0 \cdot 76$ \\
\hline $20: 0$ & $1 \cdot 1^{\mathrm{c}}$ & 0.02 & $1.3^{b}$ & 0.01 & $1.3^{\mathrm{b}}$ & 0.02 & $1.6^{\mathrm{a}}$ & 0.06 & $<0.0001$ \\
\hline$\Sigma$ SFA $^{*}$ & $21 \cdot 5^{a, b}$ & 0.10 & $22 \cdot 5^{\mathrm{a}}$ & 0.48 & $20 \cdot 8^{\mathrm{b}}$ & 0.44 & $20 \cdot 9^{b}$ & 0.16 & 0.03 \\
\hline $16: 1 n-7$ & $2 \cdot 6^{a, b}$ & 0.03 & $3.0^{\mathrm{a}}$ & 0.05 & $2 \cdot 3^{b}$ & 0.31 & $2 \cdot 1^{b}$ & 0.03 & 0.03 \\
\hline $18: 1 n-9$ & $29 \cdot 5^{a}$ & 0.43 & $25 \cdot 3^{b}$ & 0.21 & $28 \cdot 5^{a}$ & $1 \cdot 11$ & $27 \cdot 2^{a, b}$ & 0.71 & 0.01 \\
\hline $18: 1 n-7$ & 3.9 & 0.36 & $3 \cdot 6$ & 0.45 & $4 \cdot 1$ & 0.92 & $3 \cdot 4$ & 0.41 & 0.85 \\
\hline $20: 1 n-9$ & $6 \cdot 3^{\mathrm{b}}$ & 0.01 & $7 \cdot 1^{\mathrm{a}}$ & 0.08 & $6 \cdot 0^{\mathrm{b}, \mathrm{c}}$ & 0.20 & $5 \cdot 6^{c}$ & 0.20 & 0.0006 \\
\hline $22: 1 n-11$ & $0.8^{c}$ & 0.03 & $0.9^{b, c}$ & 0.01 & $1.0^{\mathrm{b}}$ & 0.04 & $1 \cdot 2^{\mathrm{a}}$ & 0.07 & 0.0007 \\
\hline$\Sigma$ MUFA $\dagger$ & $44 \cdot 1^{\mathrm{a}}$ & 0.31 & $41 \cdot 2^{b, c}$ & 0.44 & $42 \cdot 7^{a, b}$ & 0.09 & $40.6^{c}$ & 0.83 & 0.005 \\
\hline $18: 2 n-6$ & $5 \cdot 1^{\mathrm{a}}$ & 0.03 & $4 \cdot 3^{c}$ & 0.02 & $5 \cdot 1^{\mathrm{a}}$ & 0.16 & $4.7^{b}$ & 0.12 & 0.001 \\
\hline $20: 2 n-6$ & 0.4 & 0.00 & 0.4 & 0.02 & 0.5 & 0.02 & 0.4 & 0.02 & $0 \cdot 19$ \\
\hline $20: 4 n-6$ & $0.3^{\mathrm{b}}$ & 0.01 & $0 \cdot 2^{c}$ & 0.00 & $0.3^{a, b}$ & 0.01 & $0.3^{\mathrm{a}}$ & 0.00 & 0.0006 \\
\hline$\Sigma n-6 \ddagger$ & $5 \cdot 9^{\mathrm{a}}$ & 0.03 & $5 \cdot 1^{\mathrm{b}}$ & 0.06 & $6 \cdot 0^{\mathrm{a}}$ & 0.17 & $5 \cdot 6^{\mathrm{a}}$ & 0.15 & 0.003 \\
\hline $18: 3 n-3$ & $3 \cdot 2^{c}$ & 0.05 & $2 \cdot 7^{\mathrm{c}}$ & 0.03 & $5 \cdot 1^{\mathrm{b}}$ & 0.50 & $7 \cdot 2^{\mathrm{a}}$ & 0.31 & $<0.0001$ \\
\hline $20: 3 n-3$ & $0.3^{c}$ & 0.01 & $0.3^{c}$ & 0.00 & $0.5^{\mathrm{b}}$ & 0.06 & $0.7^{\mathrm{a}}$ & 0.03 & $<0.0001$ \\
\hline $20: 5 n-3$ & $9 \cdot 1^{\mathrm{b}}$ & 0.09 & $10 \cdot 8^{a}$ & 0.04 & $8 \cdot 4^{b, c}$ & 0.47 & $7 \cdot 9^{c}$ & 0.15 & 0.0002 \\
\hline $22: 5 n-3$ & 1.1 & 0.06 & 1.4 & 0.21 & 1.0 & 0.04 & 1.0 & 0.03 & 0.06 \\
\hline $22: 6 n-3$ & $12 \cdot 2$ & 0.32 & $13 \cdot 3$ & $13 \cdot 28$ & $13 \cdot 4$ & 0.28 & $13 \cdot 9$ & 0.37 & 0.06 \\
\hline$\sum n-3$ & $26.0^{c}$ & 0.44 & $28 \cdot 4^{\mathrm{b}}$ & 0.55 & $28.4^{\mathrm{b}}$ & 0.34 & $30 \cdot 6^{a}$ & 0.77 & 0.003 \\
\hline$n-6: n-3$ & $0.23^{a}$ & 0.00 & $0.18^{b}$ & 0.01 & $0.21^{a}$ & 0.00 & $0 \cdot 18^{b}$ & 0.01 & 0.001 \\
\hline $\mathrm{EPA}+\mathrm{DHA}$ & $21 \cdot 4^{\mathrm{b}}$ & 0.37 & $24 \cdot 0^{\mathrm{a}}$ & 0.40 & $21 \cdot 8^{b}$ & 0.22 & $21 \cdot 8^{b}$ & 0.44 & 0.003 \\
\hline
\end{tabular}

FO, fish oil; DHA-CA, $n$-3-rich modified canola oil.

a,b,c Mean values within a row with unlike superscript letters were significantly different $(P<0.05)$.

* Includes 15:0,17:0 and $24: 0$.

† Includes $14: 1 n-5,16: 1 n-5,16: 1 n-9,17: 1 n-7,20: 1-11$ and $22: 1 n-9$.

‡ Includes $18: 3 n-6$.

groups. The levels of TAG were affected by the inclusion level of the oils, but not by the oil source. Total TAG $(P=0 \cdot 01$, Fig. 1$)$ was significantly lower in High FO and High DHA-CA compared with Low FO and Low DHA-CA.

The total FA composition of the liver (Table 10) showed no difference in the percentage of SFA (25\% of total FA) between the dietary groups. The percentages of MUFA and total $n-6$ FA showed slightly lower percentages of MUFA (approximately $27 v .29 \%$ ) and of $n-6$ FA (approximately $5.6 v .6 .5 \%$ ) in the High groups compared with the Low groups. The opposite result was found regarding the content of total $n-3 \mathrm{FA}$, where the two 'High' diets had the highest percentages of $n-3$ FA (approximately $41 v .37 \%$ ). The percentage of EPA was lower in the liver of the two groups fed the DHA-CA diets compared with the FO diets, while $18: 3 n-3$ and DHA were higher. The two Low dietary groups (Low FO $v$. Low DHA-CA, approximately $34 \%$ ) and the two High dietary groups (High FO $v$. High DHA-CA, approximately $37 \%$ ) had similar percentages of EPA+DHA in liver.

Lipidomic analyses did not separate between families of FA, but the FA compositions of different polar and neutral lipid classes in the liver were to different degrees affected by the dietary oils (Fig. 2). The most pronounced effects were seen on the incorporation of $18: 3 \mathrm{FA}$, with a $2 \cdot 4$ - to $2 \cdot 9$-fold increase in High DHA-CA $v$. High FO in most lipid classes. The proportion of $20: 5$ FA was decreased in most polar lipids in the liver of fish fed High DHA-CA $v$. High FO, with differences from 1.2- to 1.7fold. The FA ratio of $20: 4$ increased in phosphatidyl choline (fold difference 1.3, $P=0.003$ ) and also in cholesterol ester and free FA in fish fed High DHA-CA $v$. High FO. The FA ratio of $22: 6$ was significantly enriched in phosphatidylinositol of fish fed the High DHA-CA $v$. High FO and also in cholesterol ester (both $1 \cdot 2$-fold difference, $P=0 \cdot 02$ ). Liver cholesterol was similar in all diet groups, while the DHA-CA dietary groups had increased liver content of phytosterols, primarily campesterol and sitostanol (Table 10).

There were no significant differences in the activities of the key enzymes, catalase, glutathione peroxidase and superoxide dismutase associated with oxidative stress between the dietary treatments (Fig. 3). S-Adenosyl-L-methionine is also one of the major physiological protectors against oxidative stress. For $S$-adenosylmethionine, there was both a diet effect (DHA-CA fed fish livers had higher marker levels than FO fed fish livers, $P=0.005, q=0.02$ ) and an effect of level (the high inclusion level groups had higher than the Low inclusion groups, $P=0.006$, $q=0.05$ ). GSH had a clear effect due to the oil inclusion level, with higher metabolite levels at Low inclusion compared with high inclusion $(P=0 \cdot 003, q=0 \cdot 04)$, irrespective of oil source. The GSSG was constant (not shown). As GSSG was constant, the ratio of GSSG to GSH was increased at the high inclusion levels.

The gene expression profiles in livers of salmon fed High DHACA and High FO were nearly identical. Salmon fed Low FO and Low DHA-CA diets showed highly consistent stimulation of genes in lipid and cholesterol metabolism relative to the High groups. Twenty-two up-regulated differentially expressed genes encoded 
Table 9. Lipid content (\% of wet weight) and fatty acid composition (\% of total) in erythrocytes of Atlantic salmon fed the experimental diets for $83 \mathrm{~d}$ at low $\left(12^{\circ} \mathrm{C}\right)$ water temperature

(Mean values using tank as a statistical unit ( $n 3$, being each sample represented by a pool of five fish) with their standard errors)

\begin{tabular}{|c|c|c|c|c|c|c|c|c|c|}
\hline & \multicolumn{2}{|c|}{ Low FO } & \multicolumn{2}{|c|}{ High FO } & \multicolumn{2}{|c|}{ Low DHA-CA } & \multicolumn{2}{|c|}{ High DHA-CA } & \multirow[b]{2}{*}{ ANOVA, $P$} \\
\hline & Mean & SE & Mean & SE & Mean & SE & Mean & SE & \\
\hline Total fat & $2 \cdot 6$ & 0.13 & $2 \cdot 6$ & 0.03 & $2 \cdot 4$ & 0.05 & $2 \cdot 6$ & 0.26 & 0.74 \\
\hline $14: 0$ & $1.3^{b}$ & 0.05 & $1.6^{a}$ & 0.09 & $1.3^{b}$ & 0.03 & $1 \cdot 3^{\mathrm{b}}$ & 0.03 & 0.01 \\
\hline $16: 0$ & $15 \cdot 1^{a, b}$ & 0.16 & $15 \cdot 3^{a}$ & 0.10 & $14 \cdot 5^{a, b}$ & 0.46 & $14 \cdot 2^{\mathrm{b}}$ & 0.22 & 0.08 \\
\hline $18: 0$ & $2 \cdot 6$ & 0.09 & $2 \cdot 4$ & 0.08 & $2 \cdot 6$ & 0.07 & $2 \cdot 6$ & 0.09 & 0.25 \\
\hline$\Sigma \mathrm{SFA}^{*}$ & $20 \cdot 2^{a, b}$ & 0.12 & $20 \cdot 6^{a}$ & 0.29 & $19 \cdot 6^{b}$ & 0.29 & $19 \cdot 5^{\mathrm{b}}$ & 0.06 & 0.02 \\
\hline $16: 1 n-7$ & $1.5^{\mathrm{a}}$ & 0.03 & $1.5^{\mathrm{a}}$ & 0.08 & $1 \cdot 2^{\mathrm{b}}$ & 0.04 & $1 \cdot 2^{b}$ & 0.05 & 0.005 \\
\hline $18: 1 n-11$ & $1.3^{\mathrm{b}}$ & 0.07 & $1.5^{\mathrm{a}}$ & 0.01 & $1 \cdot 2^{b}$ & 0.02 & $1 \cdot 3^{\mathrm{b}}$ & 0.01 & 0.005 \\
\hline $18: 1 n-9$ & $18 \cdot 1^{\mathrm{a}}$ & 0.36 & $14 \cdot 5^{\mathrm{c}}$ & 0.73 & $17 \cdot 6^{a, b}$ & 0.33 & $15 \cdot 5^{\mathrm{b}, \mathrm{c}}$ & 1.07 & 0.02 \\
\hline $18: 1 n-7$ & $1.9^{b}$ & 0.01 & $1.9^{\mathrm{b}}$ & 0.05 & $2 \cdot 0^{a, b}$ & 0.05 & $2 \cdot 1^{\mathrm{a}}$ & 0.08 & 0.05 \\
\hline $20: 1 n-9$ & $4 \cdot 2^{a, b}$ & 0.06 & $4 \cdot 3^{a}$ & 0.12 & $3 \cdot 8^{b, c}$ & 0.15 & $3 \cdot 6^{c}$ & 0.15 & 0.02 \\
\hline $22: 1 n-11$ & $3.5^{\mathrm{a}}$ & 0.17 & $3 \cdot 7^{\mathrm{a}}$ & 0.12 & $3.0^{\mathrm{b}}$ & $0 \cdot 10$ & $3 \cdot 0^{\mathrm{b}}$ & 0.12 & 0.008 \\
\hline$\Sigma$ MUFA $\dagger$ & 33.9 & 0.61 & 30.9 & $1 \cdot 16$ & 32.7 & 0.10 & 30.9 & 1.12 & 0.11 \\
\hline $18: 2 n-6$ & $3.0^{\mathrm{a}}$ & 0.11 & $2 \cdot 4^{\mathrm{c}}$ & 0.02 & $3 \cdot 2^{\mathrm{a}}$ & 0.05 & $2 \cdot 7^{b}$ & 0.08 & 0.0003 \\
\hline $20: 4 n-6$ & 0.9 & 0.05 & 0.9 & $0 \cdot 10$ & 0.9 & 0.11 & 0.8 & 0.09 & 0.85 \\
\hline$\sum n-6 \neq$ & $6 \cdot 4$ & 0.05 & $5 \cdot 6$ & 0.25 & 6.7 & 0.56 & $6 \cdot 1$ & 0.33 & 0.21 \\
\hline $18: 3 n-3$ & $1.3^{\mathrm{c}}$ & 0.05 & $1 \cdot 1^{\mathrm{c}}$ & 0.01 & $2 \cdot 4^{\mathrm{b}}$ & 0.11 & $3 \cdot 3^{a}$ & 0.15 & $<0.0001$ \\
\hline $18: 4 n-3$ & 0.2 & 0.09 & nd & & 0.2 & 0.12 & nd & & \\
\hline $20: 3 n-3$ & $0.2^{b, c}$ & 0.02 & $0.2^{c}$ & 0.09 & $0.5^{a, b}$ & 0.06 & $0.7^{\mathrm{a}}$ & 0.06 & 0.0009 \\
\hline $20: 4 n-3$ & 0.7 & 0.07 & 0.7 & 0.01 & 0.6 & 0.06 & 0.4 & 0.21 & 0.3 \\
\hline $20: 5 n-3$ & $6 \cdot 1^{\mathrm{b}}$ & 0.10 & $6 \cdot 8^{a}$ & 0.29 & $5 \cdot 2^{\mathrm{c}}$ & 0.08 & $5 \cdot 2^{c}$ & 0.10 & 0.0003 \\
\hline $22: 5 n-3$ & 1.6 & 0.15 & 1.7 & 0.06 & 1.4 & 0.24 & $1 \cdot 1$ & 0.52 & 0.56 \\
\hline $22: 6 n-3$ & $27 \cdot 3$ & 0.54 & 30.1 & 0.66 & 28.3 & $1 \cdot 11$ & $30 \cdot 1$ & 0.62 & 0.08 \\
\hline$\sum n-3$ & 37.4 & 0.66 & $40 \cdot 6$ & 1.04 & 38.6 & 0.88 & $40 \cdot 8$ & 0.90 & 0.07 \\
\hline$n-6: n-3$ & 0.17 & 0.00 & 0.14 & 0.00 & 0.17 & 0.02 & 0.15 & 0.01 & 0.1 \\
\hline$n-3$ index & 33.4 & $0.6^{b}$ & $37 \cdot 1$ & $0.9^{\mathrm{a}}$ & 33.7 & $1 \cdot 1^{\mathrm{b}}$ & 35.6 & $0 \cdot 6^{\mathrm{a}, \mathrm{b}}$ & 0.05 \\
\hline
\end{tabular}

FO, fish oil; DHA-CA, $n$-3-rich modified canola oil; nd, not determined.

a,b,c Mean values within a row with unlike superscript letters were significantly different $(P<0.05)$.

* Includes 15:0, 17:0, 20:0, 22:0 and $24: 0$

$\dagger$ Includes $14: 1 n-5,16: 1 n-5,16: 1 n-9,17: 1 n-7,20: 1 n-11,20: 1 n-7,22: 1 n-7$ and $24: 1 n-9$

$\ddagger$ Includes $16: 2 n-6,18: 3 n-6,20: 2 n-6,20: 3 n-6$ and $22: 4 n-6$.

seventeen proteins with key roles in lipid and cholesterol metabolism (Table 11). Eighteen genes encode twelve enzymes of terpenoid backbone and steroid biosynthesis (diphosphomevalonate decarboxylase, farnesyl diphosphate synthase, 7-dehydrocholesterol reductase, isopentenyl-diphosphate $\Delta$-isomerase, lanosterol 14- $\alpha$ demethylase, lanosterol synthase, mevalonate kinase, squalene mono-oxygenase, squalene synthase, stearoyl-CoA desaturase b, sterol-4- $\alpha$-carboxylate 3 -dehydrogenase and sterolC5-desaturase). FA binding protein is required for transportation of highly lipophilic compounds, while insulin-induced gene 1 and lipin control steroid and FA metabolism at different levels. The expression differences of genes involved in lipid and steroid metabolism were related to the levels of $n$-3 LC-PUFA in the diets, but not to the source of these FA, as shown in Table 11. The microarray analysis revealed no significant differences in transcription of genes associated with stress, apoptosis, inflammation, xenobiotic metabolism or any other processes that might indicate adverse effects of the diets (data not shown).

\section{Gene expression and histological analyses of the intestine}

The histological analyses of intestinal morphology revealed no differences between the dietary groups (data not shown). Gene expression analysis of intestine tissue did not show any significant differences in expression of markers for FA oxidation (aco, cpt1), FA synthesis (fas, scd1, scd2), stress ( $b s p 70)$, inflammation (cox2) or oxidative stress ( $n r f 2$, cat, sod1s, gpx2) between FO and DHA-CA for either the Low or the High groups. The High DHA-CA had a small, but significantly higher expression level of the apoptosis marker bax compared with the High FO group (online Supplementary Table S2).

\section{Discussion}

The major overall aim of the two fish feeding trials was to rigorously investigate the suitability and possible fish health safety risk associated with the use of oil from a newly developed GM canola crop (DHA-CA) as an $n$-3 FA source in feed for Atlantic salmon. The experiments used different fish populations, water temperatures and sources of raw ingredients to provide a robust assessment of DHA-CA in varying experimental conditions. Very small fingerlings were chosen as the target life stage as they undergo extremely rapid growth and are highly responsive to dietary changes due to their heightened sensitivity.

\section{Influence of $\mathrm{n}$-3-rich modified canola oil on culture performance}

The experimental fish showed a 12 - and 20 -fold increase in body weights at 12 and $16^{\circ} \mathrm{C}$, respectively, over the course of both experiments. The specific growth rate was higher in the hightemperature experiment, with Australian strains adapted to warm water conditions. Thermal growth coefficient indicated both cohorts grew similarly well at their respective temperatures. 
Table 10. Lipid content (\% of wet weight), fatty acid composition (\% of total), and sterols ( $\mathrm{mg} / \mathrm{kg}$ ) in the liver of Atlantic salmon fed the experimental diets for $83 \mathrm{~d}$ at low $\left(12^{\circ} \mathrm{C}\right)$ water temperature

(Mean values using tank as a statistical unit ( $n 3$, being each sample represented by a pool of five fish) with their standard errors)

\begin{tabular}{|c|c|c|c|c|c|c|c|c|c|}
\hline & \multicolumn{2}{|c|}{ Low FO } & \multicolumn{2}{|c|}{ High FO } & \multicolumn{2}{|c|}{ Low DHA-CA } & \multicolumn{2}{|c|}{ High DHA-CA } & \multirow[b]{2}{*}{ ANOVA, $P$} \\
\hline & Mean & SE & Mean & SE & Mean & SE & Mean & SE & \\
\hline Total fat & $6 \cdot 3$ & 0.66 & $6 \cdot 4$ & 0.25 & $6 \cdot 3$ & 0.23 & $5 \cdot 8$ & 0.27 & 0.65 \\
\hline $14: 0$ & $1 \cdot 6^{a, b}$ & 0.07 & $1.8^{\mathrm{a}}$ & 0.12 & $1.4^{\mathrm{b}}$ & 0.03 & $1.4^{b}$ & 0.04 & 0.02 \\
\hline $16: 0$ & $18 \cdot 8$ & 0.54 & 18.5 & $0 \cdot 17$ & 18.5 & 0.23 & $18 \cdot 3$ & 0.21 & 0.76 \\
\hline $18: 0$ & 4.4 & 0.20 & 4.4 & $0 \cdot 16$ & 4.5 & 0.07 & 4.7 & 0.13 & 0.39 \\
\hline$\Sigma$ SFA $^{*}$ & $25 \cdot 6$ & 0.87 & $25 \cdot 6$ & 0.28 & $25 \cdot 5$ & 0.32 & $25 \cdot 7$ & 0.27 & 0.99 \\
\hline $16: 1 n-7$ & $1.8^{\mathrm{a}}$ & 0.10 & $1 \cdot 5^{a, b}$ & $0 \cdot 10$ & $1.4^{\mathrm{b}}$ & 0.07 & $1.3^{\mathrm{b}}$ & 0.06 & 0.02 \\
\hline $16: 1 n-9$ & 0.4 & 0.04 & 0.4 & 0.00 & 0.4 & 0.02 & 0.4 & 0.01 & 0.93 \\
\hline $18: 1 n-9$ & $23 \cdot 3^{a}$ & 0.59 & $19 \cdot 1^{\mathrm{c}}$ & 0.47 & $21 \cdot 7^{a, b}$ & 0.29 & $20 \cdot 3^{b, c}$ & 0.59 & 0.002 \\
\hline $20: 1 n-7$ & $3 \cdot 3^{b}$ & 0.07 & $3.7^{a}$ & 0.07 & $3 \cdot 2^{b, c}$ & 0.12 & $3 \cdot 0^{c}$ & $0 \cdot 10$ & 0.004 \\
\hline $22: 1 n-11$ & $0.5^{c}$ & 0.08 & $0.6^{b, c}$ & 0.03 & $0.8^{a, b}$ & 0.13 & $1.0^{\mathrm{a}}$ & 0.03 & 0.01 \\
\hline$\Sigma$ MUFA† & $30 \cdot 3^{a}$ & 0.87 & $26 \cdot 7^{\mathrm{b}}$ & 0.35 & $28 \cdot 4^{\mathrm{b}}$ & 0.29 & $26 \cdot 9^{\mathrm{b}}$ & 0.65 & 0.008 \\
\hline $18: 2 n-6$ & $3 \cdot 0^{\mathrm{a}}$ & 0.04 & $2 \cdot 3^{b}$ & 0.07 & $3.0^{\mathrm{a}}$ & 0.07 & $2 \cdot 6^{\mathrm{b}}$ & 0.16 & 0.003 \\
\hline $20: 2 n-6$ & 0.7 & 0.05 & 0.6 & 0.04 & 0.8 & 0.06 & 0.7 & 0.01 & 0.06 \\
\hline $20: 3 n-6$ & $1 \cdot 1^{\mathrm{a}}$ & 0.06 & $0.8^{\mathrm{b}}$ & 0.07 & $1.1^{\mathrm{a}}$ & 0.11 & $1 \cdot 0^{\mathrm{a}, \mathrm{b}}$ & 0.03 & 0.03 \\
\hline $20: 4 n-6$ & 1.5 & 0.09 & 1.8 & 0.09 & $1 \cdot 7$ & 0.13 & 1.5 & 0.05 & 0.13 \\
\hline$\sum n-6 \ddagger$ & $6 \cdot 3^{\mathrm{a}}$ & 0.12 & $5.5^{\mathrm{b}}$ & 0.14 & $6 \cdot 6^{\mathrm{a}}$ & 0.11 & $5 \cdot 8^{b}$ & $0 \cdot 16$ & 0.002 \\
\hline $18: 3 n-3$ & $1.0^{c}$ & 0.06 & $0.8^{c}$ & 0.04 & $1.7^{b}$ & 0.08 & $2 \cdot 4^{\mathrm{a}}$ & 0.18 & $<0.0001$ \\
\hline $20: 3 n-3$ & $0.00^{\mathrm{b}}$ & 0 & $0.2^{a, b}$ & $0 \cdot 16$ & $0.3^{a}$ & 0.07 & $0.5^{a}$ & 0.05 & 0.03 \\
\hline $20: 5 n-3$ & $5 \cdot 1^{\mathrm{a}}$ & 0.06 & $5 \cdot 5^{\mathrm{a}}$ & 0.14 & $4.7^{b}$ & 0.14 & $4 \cdot 6^{\mathrm{b}}$ & 0.07 & 0.002 \\
\hline $22: 5 n-3$ & 1.8 & 0.13 & 1.7 & 0.21 & 1.8 & 0.16 & 1.7 & 0.03 & 0.95 \\
\hline $22: 6 n-3$ & $28 \cdot 1^{b}$ & 0.86 & $32 \cdot 5^{a}$ & 0.55 & $30 \cdot 0^{a, b}$ & 0.84 & $31 \cdot 3^{a}$ & $1 \cdot 11$ & 0.03 \\
\hline$\Sigma n-3 \S$ & $36.0^{\mathrm{b}}$ & 0.85 & $40 \cdot 7^{\mathrm{a}}$ & 0.68 & $38 \cdot 5^{a, b}$ & 0.62 & $40 \cdot 5^{a}$ & 0.96 & 0.01 \\
\hline$n-6: n-3$ & $0.17^{a}$ & 0.00 & $0.14^{\mathrm{b}}$ & 0.00 & $0.17^{\mathrm{a}}$ & 0.00 & $0.14^{\mathrm{b}}$ & 0.01 & 0.0003 \\
\hline $\mathrm{EPA}+\mathrm{DHA}$ & $33 \cdot 2^{b}$ & 0.90 & $38.0^{\mathrm{a}}$ & 0.47 & $34.7^{b}$ & 0.70 & $35 \cdot 9^{\mathrm{a}, \mathrm{b}}$ & 0.15 & 0.02 \\
\hline \multicolumn{10}{|l|}{ Sterols } \\
\hline Cholesterol & 3780 & 425 & 3894 & 241 & 3840 & 262 & 3715 & 437 & 0.69 \\
\hline$\Sigma$ Phytosterols & $52 \cdot 1^{\mathrm{a}}$ & 7.9 & $51.8^{\mathrm{a}}$ & $15 \cdot 2$ & $67 \cdot 8^{\mathrm{b}}$ & $13 \cdot 4$ & $58 \cdot 2^{a, b}$ & $10 \cdot 6$ & 0.03 \\
\hline$\beta$-Sitosterol & $15 \cdot 6$ & 5.4 & $16 \cdot 7$ & $9 \cdot 2$ & $16 \cdot 6$ & 7.5 & 14.4 & $5 \cdot 2$ & 0.90 \\
\hline Campesterol & $16 \cdot 2^{\mathrm{a}}$ & $5 \cdot 1$ & $12 \cdot 1^{\mathrm{a}}$ & 5.5 & $26 \cdot 1^{\mathrm{b}}$ & 9.2 & $21 \cdot 7^{\mathrm{b}}$ & $5 \cdot 8$ & 0.0005 \\
\hline Brassicasterol & $5 \cdot 2$ & $2 \cdot 8$ & 5.9 & 1.9 & $7 \cdot 7$ & $2 \cdot 0$ & $5 \cdot 9$ & $1 \cdot 7$ & 0.39 \\
\hline Sitostanol & $2 \cdot 5^{\mathrm{a}}$ & 0.8 & $2 \cdot 6^{a, b}$ & 1.3 & $3.4^{\mathrm{b}}$ & 1.0 & $3.3^{b}$ & 0.6 & 0.04 \\
\hline
\end{tabular}

FO, fish oil; DHA-CA, $n$-3-rich modified canola oil.

a,b,c Mean values within a row with unlike superscript letters were significantly different $(P<0.05)$.

* Includes $15: 0,17: 0,20: 0,22: 0$ and $24: 0$.

† Includes $14: 1 n-5,16: 1 n-5,17: 1 n-7,18: 1 n-7,20: 1 n-11,20: 1 n-9$ and $22: 1 n-9$.

$\ddagger$ Includes $18: 3 n-6$.

$\S$ Includes $16: 2 n-3$.

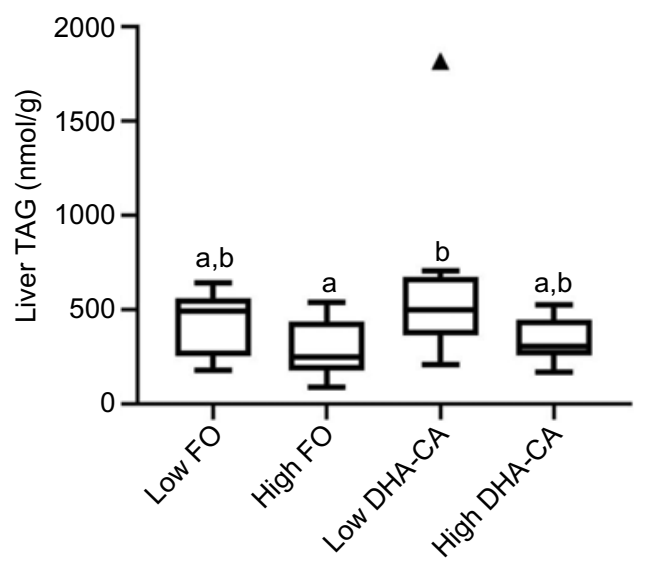

Fig. 1. Total TAG in liver from salmon fed the four different diets ( $n 9$ per diet group). TAG is given as $\mathrm{nmol} / \mathrm{g}$ liver tissue, and the figure is a Tukey box plot, showing the median, the interquartile range and the $\mathrm{min} / \mathrm{max}$, excluding outliers (which are indicated by a triangle). Two-way ANOVA showed a significant difference $(P=0.01, q=0.07)$ between the two inclusion levels (High $v$. Low) of transgenic canola oil (DHA-CA) in the diet. ${ }^{a, b}$ Between the individual diet groups, there was a significant difference between High fish oil (FO) and Low DHA$\mathrm{CA}(P=0.005, q=0.02)$.
The DHA-CA groups, relative to the corresponding FO groups, grew equally well with high survival rates $(\geq 94 \%)$ achieved in both experiments.

\section{Influence of n-3-rich modified canola oil on salmon health and safety}

Intestine and liver are particularly sensitive organs to harmful effects. The expression of genes associated with stress or toxicity, or enzyme activities related to oxidative stress, was not affected in fish fed DHA-CA. The moderate effects observed in these organs were primarily due to the inclusion level of the oil in the diet and not to the oil source, results which further strengthen the fact that our trial could not reveal any major fish health risk associated with inclusion of DHA-CA in salmon diets. This is in agreement with studies showing that both a high-EPA oil and an EPA+DHA oil from transgenic Camelina sativa included in feeds for post-smolt Atlantic salmon had no detrimental effects on fish performance, metabolic responses or the nutritional quality of fillet ${ }^{(17,33)}$.

The analysed composition of the DHA-CA oil in our trial compared with a conventional canola oil showed that it contained 


\begin{tabular}{|c|c|c|c|c|c|c|c|c|c|c|c|}
\hline \multicolumn{2}{|c|}{ High DHA-CA v. High FO } & \multicolumn{10}{|c|}{ PUFA } \\
\hline & & $\underset{\sim}{\stackrel{\infty}{\sim}}$ & ֶㅗ & 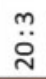 & $\begin{array}{l}\text { ¿̊ } \\
\text { }\end{array}$ & $\begin{array}{l}\stackrel{\sim}{N} \\
\text { }\end{array}$ & $\begin{array}{c}m \\
\stackrel{\infty}{\sim} \\
\sim\end{array}$ & $\underset{\sim}{\stackrel{\infty}{\sim}}$ & $\begin{array}{l}n \\
\ddot{\sim}\end{array}$ & $\begin{array}{l}\stackrel{n}{\ddot{N}} \\
\stackrel{\text { na }}{2}\end{array}$ & $\begin{array}{l}\stackrel{\varphi}{\tilde{N}} \\
\text { }\end{array}$ \\
\hline \multirow{5}{*}{$\frac{\pi}{0}$} & Phosphatidylcholine & & & & & & & & & & \\
\hline & Phosphatidylethanolamine & & & & & & & & & & \\
\hline & Phosphatidylinositol & & & & & & & & & & \\
\hline & Lysophosphatidylcholine & & & & & & & & & & \\
\hline & Lysophosphatidylethanolamine & & & & & & & & & & \\
\hline \multirow{4}{*}{ 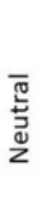 } & Cholesteryl ester & & & & & & & & & & \\
\hline & TAG & & & & & & & & & & \\
\hline & Diacylglycerol & & & & & & & & & & \\
\hline & NEFA & & & & & & & & & & \\
\hline
\end{tabular}

Scale, fold difference:

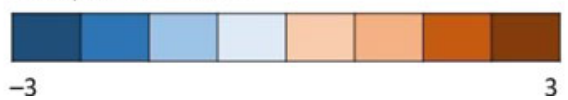

Fig. 2. Overall differences in composition of PUFA in the different lipid classes in fish fed a diet containing high levels of an $n$-3-rich modified canola oil (High DHA-CA; blue $=$ enriched in this group) $v$. in fish fed a diet containing high levels of fish oil (High FO; red $=$ enriched in this group). Colour indicates a significant difference $(P<0.05)$ between the two diet groups. The colour intensity shows the fold difference (white $=$ NS, grey $=$ not detected).

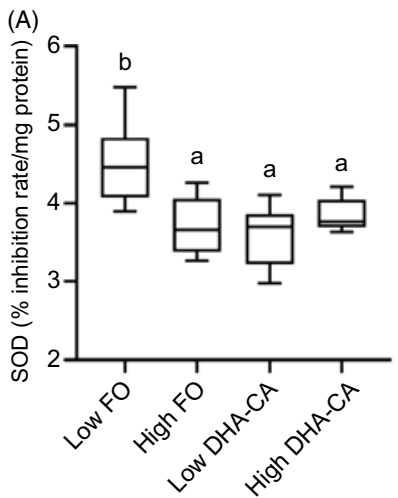

(B)

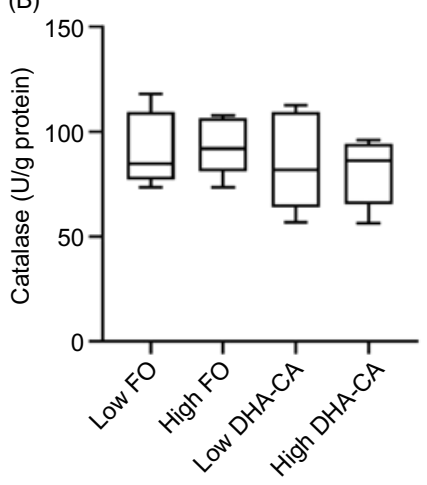

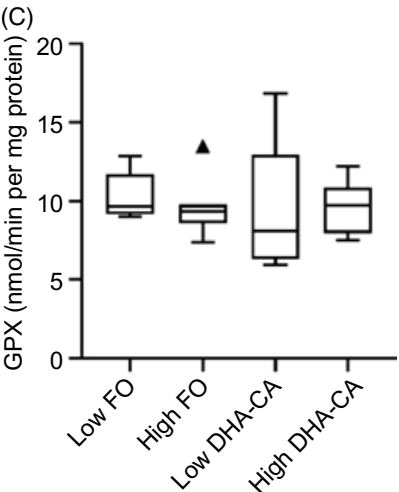
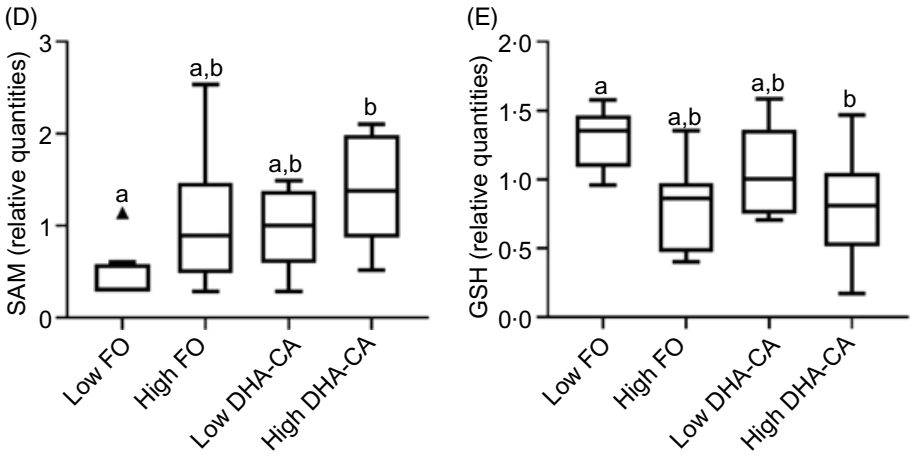

Fig. 3. Differences between the two inclusion levels (High v. Low) of transgenic canola oil (DHA-CA) in the diet. The upper panel shows the activities of three enzymes involved in the oxidative stress response in the liver: superoxide dismutase (SOD) (A), catalase (B) and glutathione peroxidase (GPX) (C). The lower panels show the levels of two metabolites related to redox management $-S$-adenosylmethionine (SAM) (D) and GSH (E) and are given as relative quantities. The graphs are Tukey box plots, showing the median, the interquartile range and the $\mathrm{min} / \mathrm{max}$, excluding outliers (which is indicated by a triangle), $n 9$ per diet group. For SAM, two-way ANOVA showed a significant difference $(P=0.006, q=0.05)$ between the two inclusion levels (High $v$. Low) of DHA-CA in the diet. a,b Between the individual diet groups, there was a significant difference between Low fish oil (FO) and High DHA-CA (values with unlike letters are significantly different, $P=0.0002, q=0.004$ ). Similarly, for GSH, two-way ANOVA showed a significant difference $(P=0.003, q=0.04)$ between the two inclusion levels. ${ }^{\mathrm{a}, \mathrm{b}}$ Between the individual diet groups, there was a significant difference between Low FO and High DHA-CA (values with unlike letters are significantly different, $P=0.006, q=0.04$ ). 
Table 11. Selected differentially expressed genes (DEG) in the liver from Atlantic salmon fed diets containing fish oil (FO) or oil from the $n$-3-rich modified canola (DHA-CA) for $83 \mathrm{~d}$ at low $\left(12^{\circ} \mathrm{C}\right)$ water temperature ${ }^{\star}$

\begin{tabular}{|c|c|c|c|}
\hline & Low FO & $\begin{array}{l}\text { Low } \\
\text { DHA-CA }\end{array}$ & $\begin{array}{l}\text { High } \\
\text { DHA-CA }\end{array}$ \\
\hline \multicolumn{4}{|l|}{ Total DEG } \\
\hline Up-regulated & 85 & 79 & 13 \\
\hline Down-regulated & 96 & 66 & 4 \\
\hline $\begin{array}{l}\text { Diphosphomevalonate } \\
\text { decarboxylase }\end{array}$ & $1 \cdot 88$ & 2.05 & 1.29 \\
\hline Endothelial lipase & $3 \cdot 14$ & $2 \cdot 44$ & 1.45 \\
\hline Farnesyl diphosphate synthase 1 & 2.94 & 3.32 & 1.68 \\
\hline Farnesyl diphosphate synthase 2 & 2.94 & 3.27 & 1.65 \\
\hline Fatty acid-binding protein.brain & 2.50 & 1.88 & $1 \cdot 15$ \\
\hline $\begin{array}{l}\text { Hydroxymethylglutaryl-CoA } \\
\text { synthase }\end{array}$ & $2 \cdot 40$ & $2 \cdot 80$ & 1.52 \\
\hline Insulin-induced gene 1 & 1.82 & $2 \cdot 01$ & 1.68 \\
\hline $\begin{array}{l}\text { Isopentenyl-diphosphate } \Delta \text { - } \\
\text { isomerase } 1\end{array}$ & 2.52 & 2.50 & 1.36 \\
\hline 7-Dehydrocholesterol reductase & 1.65 & 1.44 & 1.41 \\
\hline 7-Dehydrocholesterol reductase & 1.79 & 1.91 & 1.61 \\
\hline Lanosterol $14-\alpha$ demethylase 1 & 2.04 & 1.54 & $1 \cdot 22$ \\
\hline Lanosterol 14- $\alpha$ demethylase 2 & 1.53 & 1.81 & 1.26 \\
\hline Lanosterol synthase & $2 \cdot 14$ & 1.90 & 1.47 \\
\hline Lipin 1 & 1.80 & 1.58 & 1.63 \\
\hline Mevalonate kinase & 1.50 & 1.94 & 1.22 \\
\hline Squalene mono-oxygenase 1 & 1.34 & 1.73 & $1 \cdot 30$ \\
\hline Squalene mono-oxygenase 2 & $2 \cdot 26$ & 2.42 & 1.61 \\
\hline Squalene synthase & 1.90 & 2.00 & 1.40 \\
\hline Stearoyl-CoA desaturase b & $3 \cdot 10$ & 2.73 & $2 \cdot 69$ \\
\hline $\begin{array}{l}\text { Sterol-4- } \alpha \text {-carboxylate 3- } \\
\text { dehydrogenase } 1\end{array}$ & 1.77 & 1.58 & 1.26 \\
\hline $\begin{array}{l}\text { Sterol-4- } \alpha \text {-carboxylate 3- } \\
\text { dehydrogenase } 2\end{array}$ & 1.44 & 1.69 & 1.39 \\
\hline Sterol-C5-desaturase & 1.69 & 1.75 & 1.56 \\
\hline
\end{tabular}

* Data are presented as relative to the diet containing high levels of $\mathrm{FO}$, which is regarded as the reference level. Significantly up-regulated genes $\left(\log _{2}\right.$-expression ratio $>|0.6|(1.5$-fold), $P<0.05)$ are highlighted with red scale.

very low levels of undesirables, with levels measured far below limit of quantification of pesticides, mycotoxins, heavy metals and PAH. Further, DHA-CA also had lower levels of the typical plant oil FA - $18: 1 n-9$ and $18: 2 n-6$ - compared with a conventional canola oil and higher levels of $\gamma$-tocopherol and the healthbeneficial $n-3$ FA $-18: 3 n-3$ and DHA. Overall, these results show that the DHA-CA oil has a nutritionally beneficial composition compared with conventional canola oils in line with other $n-3$ rich oils derived from newly developed transgenic plant crops as reviewed by Tocher et al. ${ }^{(34)}$. The healthy profile of the DHA-CA oil investigated in the present study can explain that no negative effects on fish performance and health were found, even at high inclusion levels. The vitamin E (particularly $\gamma$ tocopherol) differed between DHA-CA and Ctr-CA; however, both oils were well within the normal range given for the different vitamin $\mathrm{E}$ isomers in commercial canola oil ${ }^{(35)}$

\section{Influence of n-3-rich modified canola oil on composition of whole body, muscle and erythrocytes}

The study showed no major differences in total lipid, protein or energy content of the whole body of fish in the various dietary groups, while the FA compositions were affected. Generally, for both temperature trials, lower percentages of both SFA and
MUFA and higher percentages of $18: 3 n-3$ and DHA were found in whole body of DHA-CA groups compared with the FO groups, reflecting the FA compositions of the diets. The level of EPA was moderately reduced with increased dietary inclusion of DHA-CA in the diet, due to the lower levels of this FA in DHA-CA oil. Overall, the results showed that the comparable Low FO $v$. Low DHA-CA and the High FO $v$. High DHA-CA diets resulted in equal percentages of EPA+DHA in the whole body, showing that the fish could equally utilise the EPA and DHA from traditional FO and from the DHA-CA oil. This is also in agreement with what has been observed with the EPA rich oil and the $\mathrm{EPA}+\mathrm{DHA}$ rich oil from Camelina sativa ${ }^{(33,36)}$.

An additional benefit of DHA-CA compared with conventional canola oil is the lower levels of $n-6$ FA, which results in lower body levels of $n-6$ FA when included in the diet. The $n$-6 FA are linked to pro-inflammatory pathways and generally tend to bio-accumulate with the use of terrestrial plant oils to replace $\mathrm{FO}^{(37)}$. The muscle tissue showed similar trends to the FA profiles of those of the whole body, except for lower relative percentages of MUFA and higher percentages of $n$ - 3 PUFA. This indicates the fish fillet FA profile is potentially of greater nutritional benefit to human nutrition as a result feeding DHA-CA rather than a more conventional mixture of canola oil and FO.

The different dietary groups had only minor differences in their FA composition of erythrocytes, showing that the erythrocytes are less affected by the dietary FA than whole body and muscle. There were no significant differences in the $\mathrm{EPA}+\mathrm{DHA}$ content or total $n-6$ FA content between any of the dietary groups in erythrocytes; the most marked effect was increased $18: 3 n-3$ and reduced $18: 2 n-6$ with increase in dietary DHA-CA level in the diet.

\section{Response of liver to n-3-rich modified canola oil}

Previous data have shown that genetic modification of canola can give large unintended effects on phytosterol composition (both increase and decrease) ${ }^{(38)}$. Results from our study show that dietary DHA-CA oil results in a 10-30\% higher level of phytosterols in liver than that occurs in the comparable FO-fed groups. However, a recent feeding trial with Atlantic salmon fed diets with added different phytosterol levels showed no negative effect of phytosterols up to $3000 \mathrm{mg} / \mathrm{kg}$ feed $^{(25,39)}$. In our study, the highest dietary level with the highest dose of DHACA was $739 / \mathrm{kg}$ feed, showing that no negative effects due to increased phytosterol in diet or in the liver would be expected. There was a moderately lower level of cholesterol in the diets containing the DHA-CA than in the two FO diets; however, the gene expression results from livers showed that a relatively large number of genes in the sterol biosynthesis, among them several genes with important roles in cholesterol synthesis, including lanosterol synthase, squalene synthase and sterol4 - $\alpha$-carboxylate- 3 dehydrogenase, were up-regulated in both the Low FO and Low DHA-CA groups compared with the two High groups, indicating that it is not the cholesterol level in the diet that effects the expression of these genes in liver in our study, rather the $n$ - 3 LC-PUFA levels. This is contradictory to studies showing that the cholesterol synthesis in Atlantic salmon is regulated by the dietary content of cholesterol, that 
is, high dietary levels able to inhibit and low dietary levels able to stimulate cholesterol synthesis ${ }^{(40)}$. However, other factors may also influence cholesterol metabolism. In line with our findings, previous mammalian studies have reported that EPA and DHA have hypocholesterolaemic effects by reducing hepatic cholesterol synthesis ${ }^{(41)}$

The FA that varied the most in the liver total lipids between the four experimental dietary groups was $18: 3 n-3$ (from $0 \cdot 8$ to $12.4 \%$ of total FA), and this was also reflected in the different lipid classes, with 18:3 enriched in most liver lipid classes in fish fed the DHA-CA dietary groups compared with the FO groups. While EPA+DHA was well balanced between DHA$\mathrm{CA}$ diets and their corresponding FO control groups, the DHA:EPA ratio was higher in the DHA-CA dietary groups. Hence, 20 : 5 FA decreased in the cell membrane PLs phosphatidyl choline, phosphatidylethanolamine, lyso phosphatidyl choline, cholesterol ester and TAG in the livers of fish fed the DHA-CA diets. DHA increased primarily in cholesterol ester and phosphatidylinositol. In the current diets, formulated for small fish, a high proportion of LC-PUFA was also provided from the FM fraction rather than the oils, resulting in fairly high EPA levels in all feeds above requirements. The FA 20:3 increased in most lipid classes. Although the lipid class analyses do not separate between FA families, this is probably the elongation product from $18: 3 n-3$ to $20: 3 n-3$, since this FA also increases in the total lipid fraction.

There were no significant differences in the total lipid level in the liver, while total TAG was moderately lower in both the high inclusion level of LC-PUFA irrespective of source. This is opposite to earlier findings with EPA rich oil from Camelina sativa in salmon diets which resulted in a moderate increase in liver $\mathrm{TAG}^{(33)}$. However several studies have shown that a FO rich in EPA and DHA results in decreased TAG level in liver when compared with a diet rich in plant oil, in line with our findings here $^{(5,42)}$. A factor could be $18: 1 n-9$, which was higher in the two feeds with low oil levels (Low FO and Low DHA-CA) compared with the two feeds with high oil levels (High FO and High DHA-CA) and has in previous trials/cell trials been implicated in liver lipid accumulation ${ }^{(43)}$. These data indicate a positive effect on fish liver health and metabolism of a high inclusion level of LC-PUFA, irrespective of whether this source is FO or DHA-CA.

\section{Conclusions}

Our results show that the newly developed modified canola oil (DHA-CA) has a beneficial FA profile compared with conventional plant oils, with particularly high levels of the $n-3$ FA $18: 3 n-3$ and DHA. Levels of phytosterols, vitamin $\mathrm{E}$ and minerals in the $n-3$ modified canola oil fall within the natural variation of commercial canola oils. Levels of undesirable compounds were undetectable.

Two feed trials have been carried out with salmon in fresh water, the purpose of which has been to evaluate the suitability and safety associated with the use of $n$-3-rich modified canola oil on fish performance, composition and health at two water temperatures. The fish increased their weight approx. 20 -fold at $16^{\circ} \mathrm{C}$ and 12 -fold at $12^{\circ} \mathrm{C}$. Both experiments showed high survival across all dietary groups and corresponding growth in salmon fed with a FO diet to salmon fed $n-3$ modified canola oil. The salmon fed the $n-3$ modified canola oil had the same $\mathrm{EPA}+\mathrm{DHA}$ content and proportional (\%) level in the whole body as salmon fed FO. The level of oil in the experimental feeds was the main factor affecting differential expression of genes and not the source of the oil. The level of oil in the feeds was also the determining factor for the measured health biomarkers in liver, intestine and muscle and not the source of the oil. Based on the current studies, it is concluded that the $n$-3-rich modified canola oil (DHA-CA) is as safe as other commercial canola oils and is suitable as an alternative oil source in salmon diets.

\section{Ethical statement}

The cultivation and production of DHA-CA oil was conducted with approval from the CSIRO Animal Ethics Committee, approval number A6/2016. Approved methodology was in accordance with the 'Australia Code for the care and Use of Animals for Scientific Purposes' 8th edition, and all associated legislation and regulations regarding the welfare of animals.

The feeding trial with Atlantic salmon (project FOTS ID 8378) was conducted in compliance with the Norwegian national regulation for use of experimental animals (FOR-2015-06-18-761) and classified as not requiring a specific license ( $\$ 2-\mathrm{f}$, corresponding to Directive 2010/63/EU Article 1, section 5f), since the experimental treatments were not expected to cause any distress or discomfort for the fish (FOTS decision reference no. 8378).

\section{Acknowledgements}

The authors thank Nuseed R\&D Lead Malcolm Devine, of the Omega-3 Program and Benita Boettner, Global Lead of Commercial Strategy in Nuseed for providing the DHA-CA and control CA oil and for their valuable contribution to scientific trial design and scientific discussions. The authors are grateful to Målfrid Bjerke, Leikny Fjeldstad and Jacob Wessels for skilful technical assistance. For the CSIRO led high-temperature trial, we thank David Blyth for extruding diets and technical expertise overseeing the CSIRO experiment, Simon Irvin for logistics and ethic approval, Barney Hines, Nicholas Bourne and Sue Cheers for chemical composition analysis of the CSIRO samples. Thanks to Rod Smith and Amanda Bergamin for their help with pressing suitable canola oil fractions, Richard Taylor for organising fish shipment and vaccination and Joel Slinger for receiving and acclimating fish. Thanks to Glenn Elliot and Santi Done, from Nu-Mega, for providing the control tuna oil. Finally, Surinder Singh for his knowledge of the DHA-CA oil and assistance with experimental design.

This work was funded by The Norwegian Seafood Research Fund - FHF (grant no. FHF901037).

B. R. has, as project leader, contributed to the formulation of the research questions, design of the study and writing of article. N. H. S. and M. S. contributed to the design of the study, analyses of environmental pollutants, nutrients and lipidomic analyses and writing of article. C. J. S. and P. D. N. contributed to design and analyses of the $16^{\circ} \mathrm{C}$ water temperature trial and writing of 
article. A. K. and E. L. contributed with the gene expression analyses and writing of article. G. M. B., T.-K. $\varnothing$. and M. B. contributed with design and analyses of the $12^{\circ} \mathrm{C}$ water temperature trial and writing of article.

There are no conflicts of interest.

\section{Supplementary material}

For supplementary material referred to in this article, please visit https://doi.org/10.1017/S0007114519002356

\section{References}

1. Ytrestøyl T, Aas TS \& Åsgård T (2015) Utilisation of feed resources in production of Atlantic salmon (Salmo salar) in Norway. Aquaculture 448, 365-374.

2. Shepherd CJ, Monroig O \& Tocher DR (2017) Future availability of raw materials for salmon feeds and supply chain implications: the case of Scottish farmed salmon. Aquaculture 467, 49-62.

3. Tacon AG \& Metian M (2015) Feed matters: satisfying the feed demand of aquaculture. Rev Fish Sci Aquac 23, 1-10.

4. Ruyter B, Røsjø C, Einen O, et al. (2000) Essential fatty acids in Atlantic salmon: time course of changes in fatty acid composition of liver, blood and carcass induced by a diet deficient in $n-3$ and $n-6$ fatty acids. Aquac Nutr 6, 109-117.

5. Bou M, Berge GM, Baeverfjord G, et al. (2017) Requirements of $n-3$ very long-chain PUFA in Atlantic salmon (Salmo salar $\mathrm{L}$ ): effects of different dietary levels of EPA and DHA on fish performance and tissue composition and integrity. Br J Nutr $\mathbf{1 1 7}$ 30-47.

6. Smith WL \& Murphy RC (2002) The eicosanoids: cyclooxygenase, lipoxygenase, and epoxygenase pathways. In New Comprehensive Biochemistry, vol. 36, pp. 341-371, chapter 13. New York: Elsevier.

7. Miyazaki M \& Ntambi JM (2008) Fatty acid desaturation and chain elongation in mammals. In Biochemistry of Lipids, Lipoproteins and Membranes, pp. 191-211. Amsterdam: Elsevier.

8. Nichols P, Glencross B, Petrie J, et al. (2014) Readily available sources of long-chain omega-3 oils: is farmed Australian seafood a better source of the good oil than wild-caught seafood? Nutrients 6, 1063-1079.

9. Sissener NH (2018) Are we what we eat? Changes to the feed fatty acid composition of farmed salmon and its effects through the food chain. J Exp Biol 221, jeb161521.

10. Sprague M, Dick JR \& Tocher DR (2016) Impact of sustainable feeds on omega-3 long-chain fatty acid levels in farmed Atlantic salmon, 2006-2015. Sci Rep 6, 21892.

11. Bou M (2017) Metabolism of omega-3 very long-chain polyunsaturated fatty acids in Atlantic salmon (Salmo salar L): effects of different dietary levels of EPA and DHA on fish performance and health. Philosophiae Doctor (PhD) Thesis, Norwegian University of Life Sciences.

12. Kitessa S, Abeywardena M, Wijesundera C, et al. (2014) DHAcontaining oilseed: a timely solution for the sustainability issues surrounding fish oil sources of the health-benefitting long-chain omega-3 oils. Nutrients 6, 2035-2058.

13. Petrie JR, Shrestha P, Zhou X-R, et al. (2012) Metabolic engineering plant seeds with fish oil-like levels of DHA. PLOS ONE 7, e49165.

14. Petrie JR, Shrestha P, Liu Q, et al. (2010) Rapid expression of transgenes driven by seed-specific constructs in leaf tissue: DHA production. Plant Methods $\mathbf{6}, 8$.
15. Petrie JR, Zhou X-R, Leonforte A, et al. (2019) Development of a Brassica napus (canola) crop with fish oil-like levels of DHA in seed oil (In the Press).

16. Sissener NH, Sanden M, Krogdahl A, et al. (2011) Genetically modified plants as fish feed ingredients. Can J Fish Aquat Sci 68, 563-574.

17. Betancor M, Sprague M, Usher S, et al. (2015) A nutritionallyenhanced oil from transgenic Camelina sativa effectively replaces fish oil as a source of eicosapentaenoic acid for fish. Sci Rep 5, 8104 .

18. Thomassen MS, Rein D, Berge GM, et al. (2012) High dietary EPA does not inhibit $\Delta 5$ and $\Delta 6$ desaturases in Atlantic salmon (Salmo salar L.) fed rapeseed oil diets. Aquaculture 360, $78-85$.

19. Glencross BD, Tocher DR, Matthew C, et al. (2014) Interactions between dietary docosahexaenoic acid and other long-chain polyunsaturated fatty acids on performance and fatty acid retention in post-smolt Atlantic salmon (Salmo salar). Fish Physiol Biochem 40, 1213-1227.

20. Emery JA, Norambuena F, Trushenski J, et al. (2016) Uncoupling EPA and DHA in fish nutrition: dietary demand is limited in Atlantic salmon and effectively met by DHA alone. Lipids 51, 399-412.

21. Julshamn K, Brenna J, Holland R, et al. (1999) Plasma source mass spectrometry - new developments and applications. Royal Soc Chem 241, 167-172.

22. Folch J, Lees M \& Sloane Stanley G (1957) A simple method for the isolation and purification of total lipides from animal tissues. J Biol Chem 226, 497-509.

23. Mason ME, Eager ME \& Waller GR (1964) A procedure for the simultaneous quantitative determination of glycerol and fatty acid contents of fats and oils. Anal Chem 36, 587-590.

24. Livak KJ \& Schmittgen TD (2001) Analysis of relative gene expression data using real-time quantitative PCR and the 2- $\Delta \Delta$ CT method. Methods 25, 402-408.

25. Sissener NH, Rosenlund G, Stubhaug I, et al. (2018) Tissue sterol composition in Atlantic salmon (Salmo salar L.) depends on the dietary cholesterol content and on the dietary phytosterol:cholesterol ratio, but not on the dietary phytosterol content. Br J Nutr 119, 599-609.

26. Laakso P (2005) Analysis of sterols from various food matrices. Eur J Lipid Sci Tech 107, 402-410.

27. Comité Européen de Normalisation (CEN) (1999) Foodstuffs determination of vitamin $\mathrm{E}$ by high performance liquid chromatography: measurement of alpha-, beta-, gamma- and delta-tocopherols, prEN 12822. Brussels: Comité Européen de Normalisation.

28. Graff I, Krossøy C, Gjerdevik K, et al. (2010) Influence of dietary menadione nicotinamide bisulphite (vitamin $\mathrm{K}_{3}$ ) and phylloquinone (vitamin $\mathrm{K}_{1}$ ) on Atlantic salmon (Salmo salar L.) tissue levels, determined by high-performance liquid chromatography with fluorescence detection. Aquac Nutr 16, 637-647.

29. Baudhuin P, Beaufay H, Rahman-Li Y, et al. (1964) Tissue fractionation studies. 17. Intracellular distribution of monoamine oxidase, aspartate aminotransferase, alanine aminotransferase, D-amino acid oxidase and catalase in rat-liver tissue. Biochem $J$ 92, 179.

30. Evans AM, DeHaven CD, Barrett T, et al. (2009) Integrated, nontargeted ultrahigh performance liquid chromatography/ electrospray ionization tandem mass spectrometry platform for the identification and relative quantification of the small-molecule complement of biological systems. Anal Chem 81, 6656-6667.

31. Reitman ZJ, Jin G, Karoly ED, et al. (2011) Profiling the effects of isocitrate dehydrogenase 1 and 2 mutations on the cellular metabolome. Proc Natl Acad Sci U S A 108, 3270-3275. 
32. Dehaven CD, Evans AM, Dai H, et al. (2010) Organization of GC/MS and LC/MS metabolomics data into chemical libraries. J Cheminform $\mathbf{2}, 9$.

33. Betancor M, Sprague M, Sayanova O, et al. (2015) Evaluation of a high-EPA oil from transgenic Camelina sativa in feeds for Atlantic salmon (Salmo salar $\mathrm{L}$.): effects on tissue fatty acid composition, histology and gene expression. Aquaculture 444, 1-12.

34. Tocher DR, Betancor MB, Sprague M et al. (2019) Omega-3 long-chain polyunsaturated fatty acids, EPA and DHA: bridging the gap between supply and demand. Nutrients 11, 89 .

35. Organisation for Economic Cooperation and Development (OECD) (2011) Revised consensus document on compositional considerations for new varieties of low erucic acid rapeseed (canola): key food and feed nutrients, anti-nutrients and toxicants series on the safety of novel foods and feeds, no. 24, Paris: Organisation for Economic Cooperation and Development. https://www.oecd.org/env/ehs/biotrack/49343153.pdf

36. Betancor MB, Li K, Sprague M, et al. (2017) An oil containing EPA and DHA from transgenic Camelina sativa to replace marine fish oil in feeds for Atlantic salmon (Salmo salar L.): effects on intestinal transcriptome, histology, tissue fatty acid profiles and plasma biochemistry. PLOS ONE 12, e0175415.

37. Bou M, Berge GM, Baeverfjord G, et al. (2017) Low levels of very-long-chain $n$-3 PUFA in Atlantic salmon (Salmo salar) diet reduce fish robustness under challenging conditions in sea cages. J Nutr Sci 6, e32.
38. Abidi SL, List GR \& Rennick KA (1999) Effect of genetic modification on the distribution of minor constituents in canola oil. $J$ Am Oil Chem Soc 76, 463-467.

39. Sissener NH, Liland NS, Holen E, et al. (2017) Phytosterols are not involved in the development of fatty liver in plant oil fed Atlantic salmon (Salmo salar) at high or low water temperature. Aquaculture 480, 123-134.

40. Kortner TM, Björkhem I, Krasnov A, et al. (2014) Dietary cholesterol supplementation to a plant-based diet suppresses the complete pathway of cholesterol synthesis and induces bile acid production in Atlantic salmon (Salmo salar L.). Br J Nutr 111, 2089-2103.

41. Park C, Choi J, Jin Y, et al. (2019) Eicosapentaenoic acid and docosahexaenoic acid, but not $\alpha$-linolenic acid, decreased low-density lipoprotein cholesterol synergistically with estrogen via regulation of cholesterol synthesis and clearance in ovariectomized rats. Nutr Res $66,13-21$.

42. Sissener N, Torstensen B, Owen M, et al. (2017) Temperature modulates liver lipid accumulation in Atlantic salmon (Salmo salar L.) fed low dietary levels of long-chain $n$-3 fatty acids. Aquac Nutr 23, 865-878.

43. Todorčević M, Vegusdal A, Gjøen T, et al. (2008) Changes in fatty acids metabolism during differentiation of Atlantic salmon preadipocytes; effects of $n-3$ and $n-9$ fatty acids. Biochim Biophys Acta 1781, 326-335. 